\title{
Polyphyletic genera in Xylariaceae (Xylariales): Neoxylaria gen. nov. and Stilbohypoxylon
}

\section{Konta $\mathrm{S}^{1,2,3,4}$, Hyde $\mathrm{KD}^{2,3,5}$, Phookamsak $\mathbf{R}^{2,3,6,10}, \mathrm{Xu} \mathrm{JC}^{3,6,10}$, Maharachchikumbura SSN ${ }^{7}$, Daranagama DA $^{8}$, McKenzie EHC ${ }^{9}$, Boonmee ${ }^{2,4}$, Tibpromma ${ }^{3,6,10}$, Eungwanichayapant $\mathrm{PD}^{4}$, Samarakoon $\mathrm{MC}^{2}$ and $\mathrm{Lu} \mathrm{YZ}^{1 *}$}

\author{
${ }^{1}$ School of Food and Pharmaceutical Engineering, Guizhou Institute of Technology, Guiyang 550003, People’s \\ Republic of China \\ ${ }^{2}$ Center of Excellence in Fungal Research, Mae Fah Luang University, Chiang Rai 57100, Thailand \\ ${ }^{3}$ CAS Key Laboratory for Plant Diversity and Biogeography of East Asia, Kunming Institute of Botany, Chinese \\ Academy of Science, Kunming 650201, Yunnan, People's Republic of China \\ ${ }^{4}$ School of Science, Mae Fah Luang University, Chiang Rai. 57100, Thailand \\ ${ }^{5}$ Innovative Institute of Plant Health, Zhongkai University of Agriculture and Engineering, Haizhu District, Guangzhou \\ 510225, People's Republic of China \\ ${ }^{6}$ East and Central Asia Regional Office, World Agroforestry Centre (ICRAF), Kunming 650201, Yunnan, People's \\ Republic of China \\ ${ }^{7}$ School of Life Science and Technology, University of Electronic Science and Technology of China, Chengdu, 611731, \\ People's Republic of China \\ ${ }^{8}$ Department of Plant and Molecular Biology, Faculty of Science, University of Kelaniya, Kelaniya, Sri Lanka \\ ${ }^{9}$ Manaaki Whenua Landcare Research, Private Bag 92170, Auckland, New Zealand \\ ${ }^{10}$ Honghe Center for Mountain Futures, Kunming Institute of Botany, Chinese Academy of Sciences, Honghe County \\ 654400, Yunnan, People's Republic of China
}

Konta S, Hyde KD, Phookamsak R, Xu JC, Maharachchikumbura SSN, Daranagama DA, McKenzie EHC, Boonmee S, Tibpromma S, Eungwanichayapant PD, Samarakoon MC, Lu YZ 2020 - Polyphyletic genera in Xylariaceae (Xylariales): Neoxylaria gen. nov. and Stilbohypoxylon. Mycosphere 11(1), 2629-2651, Doi 10.5943/mycosphere/11/1/17

\begin{abstract}
Several genera in Xylariaceae are polyphyletic in phylogenetic trees and represent more than one distinct genus. However, it is challenging to resolve these genera that are often phylogenetically distantly related, because many taxa have never been recollected and sequenced. Those that have been named and sequenced often lack documented characters or herbarium material. In this paper, we use descriptive morphology of fresh collections, and molecular data to resolve some taxonomic problems in Xylariaceae. During the of microfungi on palms in Thailand, we collected several novel xylariaceous taxa. Herein, we introduce a new genus Neoxylaria which is distantly related to Xylaria sensu stricto and a new species Stilbohypoxylon elaeidis. Neoxylaria is characterized by relatively small stromata with conspicuously exposed perithecial contours under a narrowly striped outer layer. Neoxylaria accommodates a species morphologically similar to Xylaria juruensis, which was also collected from palm material in Brazil and $X$. queenslandica collected from Archontophoenix alexandrae in Australia. As no molecular data exists for these old collections, we have linked them with morphology to our fresh collection and use both molecular data and morphology to introduce the new genus. Neoxylaria juruensis (Henn.) Konta \& K.D. Hyde, comb. nov. and N. queenslandica (Joanne E. Taylor, K.D. Hyde \& E.B.G. Jones) Konta \& K.D. Hyde, comb. nov. are therefore established. Multigene phylogenetic analysis shows that our new species (S. elaeidis) clusters with Stilbohypoxylon sensu stricto (Stilbohypoxylon clade II) and
\end{abstract}


clarifies the nature of the genus. The new species differs from other species in having solitary, smooth stromata and forms synnemata-like structures on the host, but not on the stroma. The novel taxa introduced here are supported by multigene phylogeny and morphology. Comprehensive morphological descriptions, illustrations and a phylogenetic tree to show the placement of new taxa are provided.

Keywords - 3 new taxa - palmicolous fungi - phylogeny - Sordariomycetes - taxonomy - Thai fungi

\section{Introduction}

Xylariaceae has a long history of study and is one of the largest and most diverse families of Ascomycota (Fröhlich \& Hyde 2000, Tang et al. 2009, Stadler et al. 2013, Koyani et al. 2016, Daranagama et al. 2018). Most xylariaceous species are saprobes or endophytes, while a few are considered to be plant pathogens (Rogers 2000, Okane et al. 2008, Stadler et al. 2013, Husbands \& Aime 2018, Pourmoghaddam et al. 2018). Xylariaceous taxa exhibit high diversity in tropical regions and produce a high number of bioactive secondary metabolites (Fröhlich \& Hyde 2000, Stadler \& Hellwig 2005, Senanayake et al. 2015, Adnan et al. 2018a, Chen et al. 2018, Elias et al. 2018, Cedeño-Sanchez et al. 2020). Over time, several genera have either been included or excluded from Xylariaceae and the family limits remain unstable (Daranagama et al. 2016, 2018, Tibpromma et al. 2017, Fournier et al. 2018a, Voglmayr et al. 2018, Wendt et al. 2018). The evolutionary relationships of Xylariaceae with other related families using molecular clock evidence have been studied by Samarakoon et al. (2016), Hongsanan et al. (2017) and Hyde et al. (2017, 2020). Samarakoon et al. (2016) estimated that the crown node ages of Xylariaceae and Microdochiaceae were during the Late Mesozoic (66-100 Mya). Hongsanan et al. (2017) and Hyde et al. (2017) also concluded that the divergence times of familial ranks in Sordariomycetes should be around 50-150 Mya. Hyde et al. (2020) confirmed the familial status of Xylariaceae in the subclass Xylariomycetidae and estimated the divergence time for Xylariomycetidae at 278 Mya. Wijayawardene et al. (2018) listed 44 genera in Xylariaceae based on the updated phylogenetic relationships of Daranagama et al. (2018) and Wendt et al. (2018). Hyde et al. (2020) redefined the families of Sordariomycetes based on phylogenetic analyses and divergence estimates coupled with morphology. They accepted 32 genera for Xylariaceae, and this was followed by Wijayawardene et al. (2020).

Xylaria was introduced by Schrank (1789) as the generic type of Xylariaceae. Xylaria is the largest genus of Xylariaceae with $X$. hypoxylon as the type species (Greville 1824, Peršoh et al. 2009). Xylaria species are saprobes on dead wood and endophytes occurring in living plants and are sometimes associated with termites (Hsieh et al. 2010, Daranagama et al. 2018). The important characteristics of this genus are stromata that are extremely variable in size, colour, and shape; subglobose perithecia, immersed to slightly exposed in perithecia mounds; 8-spored asci that are unitunicate, cylindrical, long-pedicellate, with $\mathrm{J}+$, apical ring and uniseriate ascospores, that are ellipsoid-inequilateral, medium to dark brown, containing two large guttules and with a germ slit. The asexual morph is geniculosporium-like, with hyaline-light brown, smooth, branched conidiophores bearing hyaline, roughened or smooth-walled, ellipsoidal conidia (Stadler et al. 2013, Maharachchikumbura et al. 2016, Daranagama et al. 2018).

Stilbohypoxylon was introduced by Hennings (1902) with the type species S. moelleri. The genus is characterized by globose to pulvinate black stromata, with scales or blunt spines on the surface, cylindrical asci, with a $\mathrm{J}+$, apical ring, brown, ellipsoidal ascospores, often with a thin mucilaginous sheath, with a straight or spiral germ slit and geniculosporium-like asexual morphs (Hennings 1902, Rogers \& Ju 1997, Petrini 2004, Daranagama et al. 2018). Rogers \& Ju (1997) redescribed the type species and introduced a new species, S. samuelsii. Hladki \& Romero (2003) accommodated two new species in this genus viz. S. macrosporum and $S$. minus. A key to the species was provided by Petrini (2004). Recently, a new record of $S$. quisquiliarum was reported from Argentina (Esteban et al. 2013). DNA sequence data are available for only two species in 
GenBank, S. elaeidicola and S. quisquiliarum. These two Stilbohypoxylon species did not resolve as a monophyletic group (Ju et al. 2007, Tang et al. 2007, 2009, Peláez et al. 2008, Hsieh et al. 2010, Daranagama et al. 2018, Wendt et al. 2018).

Both Stilbohypoxylon and Xylaria are unresolved lineages and much lumping and splitting of species has occurred over time. For example, Fröhlich \& Hyde (2000) lumped numerous collections under S. moelleri, both from palms and dicotyledonous wood. Thus, researchers must strictly consider the type when comparing genera and species. However, since few types have sequence data and only few species have been epitypified, comparison of species is rather difficult. Phylogenetic studies indicated that Stilbohypoxylon and Xylaria do not form monophyletic groups, even though they clustered within Xylariaceae (Lee et al. 2000, Hsieh et al. 2010, Senanayake et al. 2015, Maharachchikumbura et al. 2016, Hongsanan et al. 2017, Daranagama et al. 2018, Wendt et al. 2018). Daranagama et al. (2018) and Wendt et al. (2018) discussed the phylogenetic affinities of xylariaceous genera based on morphology, phylogeny, and chemotaxonomic concepts. Wendt et al. (2018) found that Xylaria clustered in three main clades within Xylariaceae, while Stilbohypoxylon formed a clade with some Xylaria species and other genera viz. Amphirosellinia, Astrocystis, and Collodiscula but without statistical support. Daranagama et al. (2018) also confirmed that Xylaria is polyphyletic in Xylariaceae; for Stilbohypoxylon, S. quisquiliarum clustered within one subclade and S. elaeidicola clustered within another subclade.

This study is a continuation of the series on palmicolous fungi in Thailand (Konta et al. 2016, 2020). The combined sequence data of ITS, RPB2 and TUB2 is used to investigate the placement of Neoxylaria and Stilbohypoxylon and their phylogenetic relationships.

\section{Materials \& Methods}

\section{Collection, isolation, and identification}

Dead palm materials were collected from two locations in Krabi and Phang-nga Provinces, Thailand, in 2014 (Fig. 1). Fungal isolates were obtained from dead petioles of palm and primary identification of the fungi was performed based on the presence of fruiting bodies, asci, and ascospores. Pure cultures were obtained using single spore isolation on a petri-dish containing malt extract agar (MEA) medium and incubated at $25-28^{\circ} \mathrm{C}$ overnight (Konta et al. 2016). Culture characteristics were recorded after incubation at $25-28^{\circ} \mathrm{C}$ for 14 days.

Morphological characteristics were examined using a Motic SMZ 168 series stereomicroscope and photographed using an Axio camera fitted on the Zeiss Discover V8 stereomicroscope. Micro-morphological structures were photographed using a Canon 600D camera on Nikon ECLIPSE 80i microscope. Distilled water, lactic acid and/or lacto glycerol were used as mounting agents, Meltzer's reagent was used for testing amyloid reaction of the apical ring structures. Fungal structures were measured using Image Framework software (IFW v. 0.9.7). Photo plates were processed using Adobe Photoshop CS6 (Adobe Systems, USA). The holotype specimens were deposited in the herbarium of Mae Fah Luang University (Herb. MFLU) and extype cultures in Mae Fah Luang Culture Collection (MFLUCC), Chiang Rai, Thailand. Facesoffungi and Index Fungorum numbers are registered as outlined in Jayasiri et al. (2015) and Index Fungorum (2020).

\section{DNA extraction and PCR amplification}

The DNA was extracted from the mycelia of 14 days old fungal cultures using the Biospin Fungus Genomic DNA Extraction Kit (BioFlux ${ }^{\circledR}$, P.R. China) following the manufacturer's protocol. The internal transcribed spacer (ITS), partial RNA polymerase II second largest subunit (RPB2) and partial $\beta$-tubulin (TUB2) loci were subjected to PCR amplification and sequencing using specific primers and PCR conditions (Table 1). The total volume of PCR mixtures for amplifications were carried out in a $25 \mu \mathrm{l}$ reaction volume containing, $8.5 \mu \mathrm{l}$ of $\mathrm{dd}_{2} \mathrm{O}, 12.5 \mu \mathrm{l}$ of 2× Easy Taq PCR Super Mix (mixture of Easy Taq TM DNA Polymerase, dNTPs and optimized buffer (Beijing Trans Gen Biotech Co., Chaoyang, Beijing, P.R. China), $2 \mu$ of DNA template, and 
$1 \mu \mathrm{l}$ of each forward and reverse primers $(10 \mathrm{pM})$. The quality of PCR products was checked on $1 \%$ agarose gel electrophoresis stained with $4 \mathrm{~S}$ green nucleic acid (Life Science Products \& Services Cat. Songjiang, Shanghai, P.R. China). Purification and sequencing of PCR products were carried out by Sangon Biotech Co., Shanghai, China. Consensus sequences were generated using SeqMan software (DNASTAR). The newly generated sequences were deposited in GenBank (Table 2).
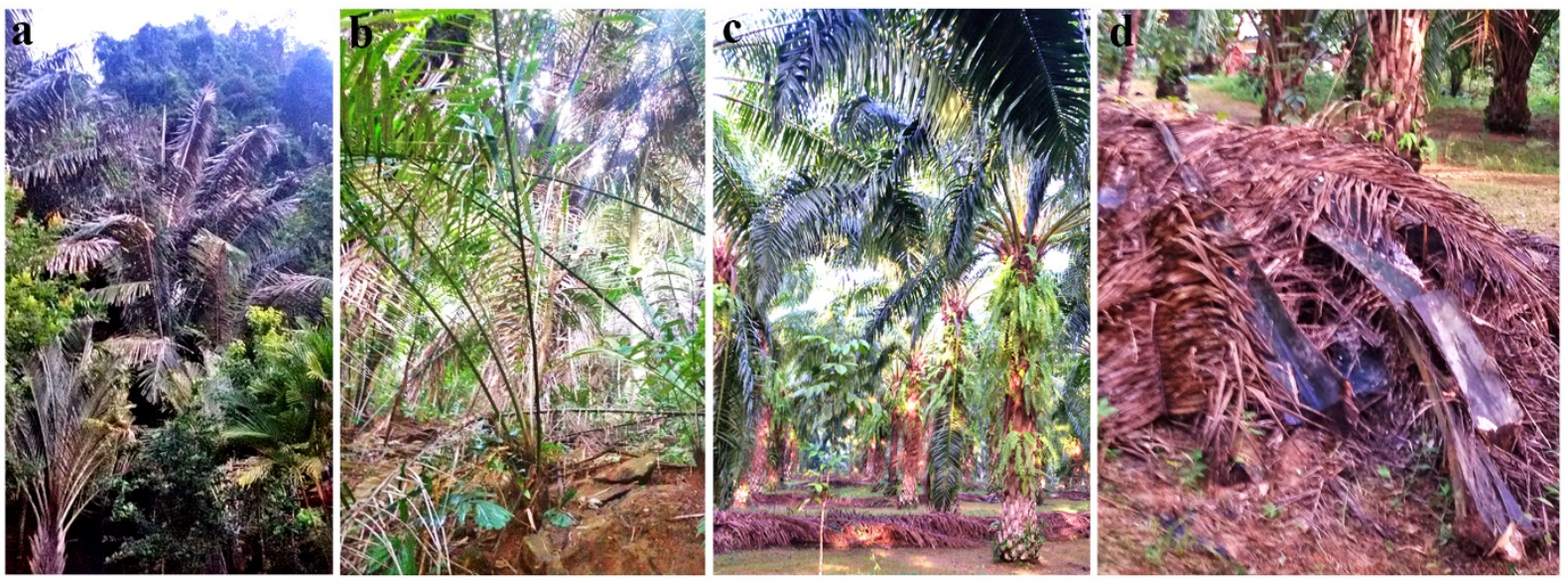

Figure 1 - a A forest in Phang-nga Province (the collection site of Neoxylaria arengae). b Arenga pinnata (Arecaceae). c An oil palm plantation in Krabi Province (the collection site of Stilbohypoxylon elaeidis). d Palm samples (Elaeis guineensis).

Table 1 Details of genes/loci with PCR primers and PCR conditions.

\begin{tabular}{|c|c|c|c|}
\hline Genes/loci & Primers & PCR conditions & References \\
\hline ITS & ITS5/ITS4 & $\begin{array}{l}\text { a; } 95^{\circ} \mathrm{C}: 30 \mathrm{~s}, 55^{\circ} \mathrm{C}: 50 \mathrm{~s}, 72^{\circ} \mathrm{C}: 30 \mathrm{~s} \\
\text { (35 cycles); }{ }^{\mathrm{c}}\end{array}$ & White et al. (1990) \\
\hline RPB2 & fRPB2-5f/fRPB2-7cR & $\begin{array}{l}\text { b; } 95^{\circ} \mathrm{C}: 1 \mathrm{~min}, 54^{\circ} \mathrm{C}: 2 \mathrm{~min}, 72^{\circ} \mathrm{C}: 1.5 \mathrm{~min} \\
\text { (35 cycles); }{ }^{\mathrm{c}}\end{array}$ & Liu et al. (1999) \\
\hline TUB2 & T1/ T22 & b; $94^{\circ} \mathrm{C}: 1 \mathrm{~min}, 52^{\circ} \mathrm{C}: 1 \mathrm{~min}, 72^{\circ} \mathrm{C}: 1.5 \mathrm{~min} ;{ }^{\mathrm{c}}$ & $\begin{array}{l}\text { O’Donnell \& } \\
\text { Cigelnik (1997) }\end{array}$ \\
\hline
\end{tabular}

${ }^{\mathrm{a}}$ Initiation step of $94^{\circ} \mathrm{C}: 3 \mathrm{~min} .{ }^{\mathrm{b}}$ Initiation step of $95^{\circ} \mathrm{C}: 5 \mathrm{~min} .{ }^{\mathrm{c}}$ Final elongation step of $72^{\circ} \mathrm{C}$ : $10 \mathrm{~min}$ and final hold at $4^{\circ} \mathrm{C}$

\section{Phylogenetic analyses}

Consensus sequences were subjected to BLAST searches in the NCBI GenBank database (http://blast.ncbi.nlm.nih.gov/). Sequence data were retrieved from GenBank following recent studies (Hsieh et al. 2010, Daranagama et al. 2018, Ju et al. 2018, Wendt et al. 2018). Sequences of the ITS, RPB2 and TUB2 were analyzed individually and in combination. Alignments were processed with MAFFT v. 7.372 (Katoh et al. 2017) and manually improved where necessary. The sequence datasets were combined using MEGA7 (Kumar et al. 2016). Maximum likelihood analyses (ML) were performed with RAxMl GUI v.1.0. (Stamatakis 2006, Silvestro \& Michalak 2012) and Bayesian inference (BI) analysis were performed with MrBayes v3.1.2 (Huelsenbeck \& Ronquist 2001). MrModeltest v. 2.2 (Nylander 2004) was used to estimate the best fit substitution model for each locus; which resulted in GTR+I+G (ITS, RPB2) and HKY $+\mathrm{I}+\mathrm{G}$ (TUB2) substitution models under the Akaike Information Criterion (AIC). Bayesian posterior probabilities (BYPP) were determined by Markov Chain Monte Carlo sampling (MCMC) in MrBayes v3.1.2 (Huelsenbeck \& Ronquist 2001). Six simultaneous Markov chains were run for 3,000,000 generations and trees were sampled every $100^{\text {th }}$ generation. MCMC heated chain was set with a "temperature" value of 0.20 . All sampled topologies beneath the asymptote (25\%) were discarded as part of a burn-in procedure; the remaining trees were used for calculating posterior probabilities 
in the majority rule consensus tree. The phylogenetic tree was visualized in FigTree v1.4.0 (Rambaut 2006) and edited using Microsoft Office PowerPoint 2010 and Photoshop CS6. The alignments and respective phylogenetic tree were deposited in TreeBASE (submission number: 25775).

Table 2 GenBank accession numbers of the sequences used in phylogenetic analyses.

\begin{tabular}{|c|c|c|c|c|c|}
\hline Species & Isolate No. & RPB2 & TUB2 & ITS & References \\
\hline Amphirosellinia fushanensis & 91111209 (HAST) & GQ848339 & GQ495950 & GU339496 & Hsieh et al. 2010 \\
\hline Astrocystis bambusae & 89021904 (HAST) & GQ844836 & GQ495942 & GU322449 & Hsieh et al. 2010 \\
\hline Astrocystis concavispora & MFLUCC 14-0174 & KP340532 & KP406615 & KP297404 & Daranagama et al. 2015 \\
\hline Astrocystis mirabilis & 94070803 (HAST) & GQ844835 & GQ495941 & GU322448 & Hsieh et al. 2010 \\
\hline Astrocystis sublimbata & 89032207 (HAST) & GQ844834 & GQ495940 & GU322447 & Hsieh et al. 2010 \\
\hline Barrmaelia rappazii & CBS 142771 & MF488998 & MF489017 & MF488989 & Voglmayr et al. 2018 \\
\hline Barrmaelia rhamnicola & CBS 142772 & MF488999 & MF489018 & MF488990 & Voglmayr et al. 2018 \\
\hline Brunneiperidium gracilentum & MFLUCC 14-0011 & KP340528 & KP406611 & KP297400 & Daranagama et al. 2015 \\
\hline Brunneiperidium involucratum & MFLUCC 14-0009 & KP340527 & KP406610 & KP297399 & Daranagama et al. 2015 \\
\hline Clypeosphaeria mamillana & CBS 140735 & MF489001 & MH704637 & KT949897 & Jaklitsch et al. 2016, Voglmayr et al. 2018 \\
\hline Collodiscula bambusae & GZUH 0102 & KP276675 & KP276674 & KР054279 & Li et al. 2015b \\
\hline Collodiscula fangjingshanensis & GZUH0109 & KR002592 & KR002589 & KR002590 & Li et al. 2015a \\
\hline Collodiscula leigongshanensis & GZUH0107 & KR002588 & KR002587 & - & Li et al. 2015a \\
\hline Daldinia loculatoides & CBS 113279 & KY624247 & KX271246 & MH862918 & Wendt et al. 2018, Vu et al. 2019 \\
\hline Entoleuca mammata & $100 \mathrm{JDR}$ & GQ844782 & GQ470230 & GU300072 & Hsieh et al. 2010 \\
\hline Entosordaria perfidiosa & $\mathrm{EPE}=\mathrm{CBS} 142773$ & MF489003 & MF489021 & MF488993 & Voglmayr et al. 2018 \\
\hline Euepixylon sphaeriostoma & $261 \mathrm{JDR}$ & GQ844774 & GQ470224 & GU292821 & Hsieh et al. 2010 \\
\hline Hypocreodendron sanguineum & $169 \mathrm{JDR}$ & GQ844819 & GQ487710 & GU322433 & Hsieh et al. 2010 \\
\hline Hypoxylon fragiforme & MUCL 51264 & KM186296 & KX271282 & KC477229 & $\begin{array}{l}\text { Stadler et al. 2013, Daranagama et al. 2015, } \\
\text { Wendt et al. } 2018\end{array}$ \\
\hline Hypoxylon monticulosum & MUCL 54604 & KY624305 & KX271273 & KY610404 & Wendt et al. 2018 \\
\hline Kretzschmaria deusta & CBS 163.93 & KY624227 & KX271251 & KC477237 & Stadler et al. 2013 \\
\hline Kretzschmaria guyanensis & 89062903 (HAST) & GQ844792 & GQ478214 & GU300079 & Hsieh et al. 2010 \\
\hline Kretzschmariella culmorum & 88 (JDR) & KX430045 & KX430046 & KX430043 & Johnston et al. 2016 \\
\hline Nemania abortiva & $467 \mathrm{BISH}$ & GQ844768 & GQ470219 & GU292816 & Hsieh et al. 2010 \\
\hline Nemania beaumontii & 405 (HAST, JF) & GQ844772 & GQ470222 & GU292819 & Hsieh et al. 2010 \\
\hline Nemania bipapillata & 90080610 (HAST) & GQ844771 & GQ470221 & GU292818 & Hsieh et al. 2010 \\
\hline Nemania primolutea & 91102001 (HAST) & GQ844767 & EF025607 & EF026121 & Ju et al. 2007, Hsieh et al. 2010 \\
\hline Nemania serpens & CBS 679.86 & KU684284 & KU684188 & KU683765 & U’Ren et al. 2016 \\
\hline Neoxylaria arengae & MFLUCC 15-0292 & МT502418 & - & MT496747 & This study \\
\hline Neoxylaria 'Xylaria'juruensis & 92042501 (HAST) & GQ844825 & GQ495932 & GU322439 & Hsieh et al. 2010 \\
\hline
\end{tabular}


Table 2 Continued.

\begin{tabular}{|c|c|c|c|c|c|}
\hline Species & Isolate No. & RPB2 & TUB2 & ITS & References \\
\hline Podosordaria mexicana & 176 WSP & GQ853039 & GQ844840 & GU324762 & Hsieh et al. 2010 \\
\hline Podosordaria muli & 167 WSP & GQ853038 & GQ844839 & GU324761 & Hsieh et al. 2010 \\
\hline Poronia pileiformis & 88113001 WSP & GQ853037 & GQ502720 & GU324760 & Hsieh et al. 2010 \\
\hline Poronia punctata & CBS 656.78 & - & KX271281 & KT281904 & Senanayake et al. 2015 \\
\hline Rosellinia aquila & MUCL 51703 & KY624285 & KX271253 & KY610392 & Wendt et al. 2018 \\
\hline Rosellinia buxi & 99 JDR & GQ844780 & GQ470228 & GU300070 & Hsieh et al. 2010 \\
\hline Rosellinia corticium & MUCL 51693 & KY624229 & KX271254 & KY610393 & Wendt et al. 2018 \\
\hline Rosellinia merrillii & 89112601 (HAST) & GQ844781 & GQ470229 & GU300071 & Hsieh et al. 2010 \\
\hline Rosellinia necatrix & CBS 349.36 & - & KY624310 & MH855818 & Wendt et al. 2018, Vu et al. 2019 \\
\hline Sarcoxylon compunctum & CBS 359.61 & KY624230 & KX271255 & КТ281903 & Senanayake et al. 2015 \\
\hline Stilbohypoxylon 'elaeidicola' elaeidis & JF-GUY-12-031 & - & - & MF038896 & Unpublished \\
\hline Stilbohypoxylon elaeidis & MFLUCC 15-0295a & MT502416 & MT502420 & MT496745 & This study \\
\hline Stilbohypoxylon elaeidis & MFLUCC 15-0295b & MT502417 & MT502421 & MT496746 & This study \\
\hline Stilbohypoxylon elaeidicola & Y.M.J. 173 & GQ844826 & EF025616 & EF026148 & Ju et al. 2007, Hsieh et al. 2010 \\
\hline Stilbohypoxylon elaeidicola & 94082615 (HAST) & GQ844827 & GQ495933 & GU322440 & Hsieh et al. 2010 \\
\hline Stilbohypoxylon quisquiliarum & Y.M.J. 172 & GQ853020 & EF025605 & EF026119 & Ju et al. 2007, Hsieh et al. 2010 \\
\hline Stilbohypoxylon quisquiliarum & 89091608 (HAST) & GQ853021 & EF025606 & EF026120 & Ju et al. 2007, Hsieh et al. 2010 \\
\hline Stilbohypoxylon quisquiliarum & PR39 & - & - & AY909023 & Peláez et al. 2008 \\
\hline Xylaria acuminatilongissima & 623 (HAST) & GQ853028 & GQ502711 & EU178738 & Ju \& Hsieh 2007, Hsieh et al. 2010 \\
\hline Xylaria adscendens & $865 \mathrm{JDR}$ & GQ844818 & GQ487709 & GU322432 & Hsieh et al. 2010 \\
\hline Xylaria aethiopica & YMJ 1136 & MH785222 & MH785221 & MH790445 & Fournier et al. 2018b \\
\hline Xylaria apoda & 90080804 (HAST) & GQ844823 & GQ495930 & GU322437 & Hsieh et al. 2010 \\
\hline Xylaria arbuscula & CBS 126415 & KY624287 & KX271257 & MH864101 & Wendt et al. 2018, Vu et al. 2019 \\
\hline Xylaria atrosphaerica & 91111214 (HAST) & GQ848342 & GQ495953 & GU322459 & Hsieh et al. 2010 \\
\hline Xylaria badia & 95070101 (HAST) & GQ844833 & GQ495939 & GU322446 & Hsieh et al. 2010 \\
\hline Xylaria bambusicola & 162 JDR & GQ844801 & GQ478223 & GU300088 & Hsieh et al. 2010 \\
\hline Xylaria berteri & 90112623 (HAST) & GQ848362 & AY951763 & - & Hsieh et al. 2010, 2005 \\
\hline Xylaria brunneovinosa & 720 (HAST) & GQ853023 & GQ502706 & EU179862 & Ju \& Hsieh 2007, Hsieh et al. 2010 \\
\hline Xylaria castorea & 600 PDD & GQ853018 & GQ502703 & GU324751 & Hsieh et al. 2010 \\
\hline Xylaria cf. castorea & 91092303 (HAST) & GQ853019 & GQ502704 & GU324752 & Hsieh et al. 2010 \\
\hline Xylaria cf. glebulosa & 431 (HAST, JF) & GQ848345 & GQ495956 & GU322462 & Hsieh et al. 2010 \\
\hline Xylaria cf. heliscus & 88113010 (HAST) & GQ848355 & GQ502691 & GU324742 & Hsieh et al. 2010 \\
\hline Xylaria crozonensis & 398 (HAST, JF) & GQ848361 & GQ502697 & GU324748 & Hsieh et al. 2010 \\
\hline Xylaria cubensis & 159 GENT & GQ853017 & GQ502702 & - & Hsieh et al. 2010 \\
\hline
\end{tabular}


Table 2 Continued.

\begin{tabular}{|c|c|c|c|c|c|}
\hline Species & Isolate No. & RPB2 & TUB2 & ITS & References \\
\hline Xylaria culleniae & $189 \mathrm{JDR}$ & GQ844829 & GQ495935 & GU322442 & Hsieh et al. 2010 \\
\hline Xylaria curta & 494 (HAST, JF) & GQ844831 & GQ495937 & GU322444 & Hsieh et al. 2010 \\
\hline Xylaria digitata & 919 (HAST) & GQ848338 & GQ495949 & GU322456 & Hsieh et al. 2010 \\
\hline Xylaria discolor & Y.M.J. 1280 & JQ087411 & JQ087414 & JQ087405 & Ju et al. 2012 \\
\hline Xylaria enterogena & 785 (HAST, JF) & GQ848349 & GQ502685 & GU324736 & Hsieh et al. 2010 \\
\hline Xylaria feejeensis & 91122401 (HAST) & GQ848353 & GQ502689 & GU324740 & Hsieh et al. 2010 \\
\hline Xylaria frustulosa & 92092010 (HAST) & GQ844838 & GQ495944 & GU322451 & Hsieh et al. 2010 \\
\hline Xylaria globosa & 775 (HAST, JF) & GQ848348 & GQ502684 & GU324735 & Hsieh et al. 2010 \\
\hline Xylaria grammica & 479 (HAST) & GQ844813 & GQ487704 & GU300097 & Hsieh et al. 2010 \\
\hline Xylaria haemorrhoidalis & 89041207 (HAST) & GQ848347 & GQ502683 & GU322464 & Hsieh et al. 2010 \\
\hline Xylaria hypoxylon & CBS 122620 & KY624231 & KX271279 & KY610407 & Wendt et al. 2018 \\
\hline Xylaria ianthinovelutina & 553 (HAST, JF) & GQ844828 & GQ495934 & GU322441 & Hsieh et al. 2010 \\
\hline Xylaria intracolorata & 90080402 (HAST) & GQ848354 & GQ502690 & GU324741 & Hsieh et al. 2010 \\
\hline Xylaria karyophthora & DRH059 & KY564216 & - & KY564220 & Husbands et al. 2018 \\
\hline Xylaria laevis & 419 (HAST, JF) & GQ848359 & GQ502695 & GU324746 & Hsieh et al. 2010 \\
\hline Xylaria luteostromata & 508 (HAST, JF) & GQ848352 & GQ502688 & GU324739 & Hsieh et al. 2010 \\
\hline Xylaria multiplex & 580 (HAST, JF) & GQ844814 & GQ487705 & GU300098 & Hsieh et al. 2010 \\
\hline Xylaria ophiopoda & 93082805 (HAST) & GQ848344 & GQ495955 & GU322461 & Hsieh et al. 2010 \\
\hline Xylaria oxyacanthae & 859 JDR & GQ844820 & GQ495927 & GU322434 & Hsieh et al. 2010 \\
\hline Xylaria palmicola & 604 PDD & GQ844822 & GQ495929 & GU322436 & Hsieh et al. 2010 \\
\hline Xylaria phyllocharis & 528 (HAST, JF) & GQ844832 & GQ495938 & GU322445 & Hsieh et al. 2010 \\
\hline Xylaria polymorpha & 1012 JDR & GQ848343 & GQ495954 & GU322460 & Hsieh et al. 2010 \\
\hline Xylaria reevesiae & HМH-2010g & GQ844821 & GQ495928 & GU322435 & Hsieh et al. 2010 \\
\hline Xylaria regalis & 92072001 (HAST) & GQ848357 & GQ502693 & GU324744 & Hsieh et al. 2010 \\
\hline Xylaria schweinitzii & 92092023 (HAST) & GQ848346 & GQ495957 & GU322463 & Hsieh et al. 2010 \\
\hline Xylaria scruposa & 497 (HAST, JF) & GQ848341 & GQ495952 & GU322458 & Hsieh et al. 2010 \\
\hline Xylaria spinulosa & GZUCC13016 & KM236098 & KM236099 & - & Li et al. 2015b \\
\hline Xylaria telfairii & 421 (HAST, JF) & GQ848350 & GQ502686 & GU324737 & Hsieh et al. 2010 \\
\hline Xylaria vivantii & HMH-2010h & GQ844824 & GQ495931 & GU322438 & Hsieh et al. 2010 \\
\hline
\end{tabular}

*Newly generated strains are in bold. 


\section{Results}

\section{Phylogeny}

The combined dataset (ITS, RPB2 and TUB2) comprised 93 taxa from selected species of Xylariaceae with 2,701 characters including gaps (ITS: 1-493, RPB2: 494-1,647, TUB2: 1,648-2,701). The RAxML analysis resulted in the best scoring likelihood tree selected with a final ML optimization likelihood value of -51211.148170 , which is represented in Fig. 2. The final likelihood tree was evaluated and optimized under GAMMA model parameters: with 1,431 distinct alignment patterns and $10.27 \%$ of undetermined characters or gaps. Bayesian posterior probabilities from MCMC were evaluated with a final average standard deviation of split frequencies less than 0.01 .

ITS-RPB2-TUB2 phylogeny shows that our strain MFLUCC 15-0292 clusters with "Xylaria juruensis" (92042501HAST), basal to Stilbohypoxylon clade II with high statistical support (100\% ML, 1.00 BYPP). The strains MFLUCC 15-0295a and MFLUCC 15-0295b formed a clade with Stilbohypoxylon clade II as a sister to S. elaeidicola with high statistical support (95\% ML, 0.99 BYPP). Stilbohypoxylon quisquiliarum (Stilbohypoxylon clade I) formed a separate clade and clustered with Xylaria "PO” clade II (58\% ML, 0.95 BYPP, Fig. 2).

Xylaria is polyphyletic in Xylariaceae, which is in agreement with previous studies (Daranagama et al. 2018, Wendt et al. 2018). In this study, Xylaria can be separated into seven "PO" clades, two "HY" clades and a single "TE" clade. Delimitation of the Xylaria clades are mostly restricted to their morphological characteristics and habitats. Xylaria "HY" clades are represented by $X$. hypoxylon (sensu stricto, "HY" clade II) and taxa in these clades have pointed or sterile stromal apices. The Xylaria "PO" clades are represented by $X$. polymorpha where most taxa in these clades have blunt or fertile stromatal apices. The Xylaria "TE" clade is represented by taxa associated with termite nests.

\section{Taxonomy}

Neoxylaria Konta \& K.D. Hyde, gen. nov.

Index Fungorum number: IF556650; Facesoffungi number: FoF06239

Etymology - In reference to the morphological resemblance to Xylaria

Saprobic on palms (Arecaceae). Sexual morph: Stromata erect, coriaceous, solitary, cylindrical, simple to branched from the base, arising separately or in small bundles, stipe (stem) with brown hairy-tomentose, fertile part, bearing exposed outlines, apex sterile with globose perithecia, free perithecia scattered along with a filiform stroma, arranged in zigzag or in rows, visible as black, thick, surface finely cracked, sterile apex attenuated conical. Perithecia immersed in stromatic tissues, globose, ostiolate with periphyses. Peridium thick-walled, composed of several layers, outwardly, comprising dark brown cells of textura angularis and inwardly, thick-walled, comprising hyaline to pale brown cells of textura prismatica. Ostiole hyaline, papillate, with a central periphyses ostiolar canal and brown to black surrounding disc appear on the surface. Paraphyses hyaline, filamentous, cylindrical, septate, unbranched. Asci 6-8-spored, unitunicate, cylindrical, long pedicellate, apically rounded, with a $\mathrm{J}+$, apical ring, inverted hat-shaped. Ascospores uniseriate, hyaline to pale brown when immature, dark brown at maturity, broad fusoid, unicellular, a lot of small guttules when immature, two large guttules at maturity, smooth-walled, with a straight germ slit throughout ascospore-length. Asexual morph: Undetermined.

Type species - Neoxylaria arengae Konta \& K.D. Hyde

Notes - Species of Xylaria cluster in ten subclades in the phylogenetic tree (Fig. 2) indicating that the genus is polyphyletic representing three major clades as Xylaria "HY", "PO" and "TE". The type species, $X$. hypoxylon clusters in Xylaria "HY" clade II which can be regarded as Xylaria sensu stricto. However, it is hard to justify the other clades (Xylaria sensu lato) as new genera without examining old types of these species or obtaining well-defined and identified fresh collections with molecular data. 


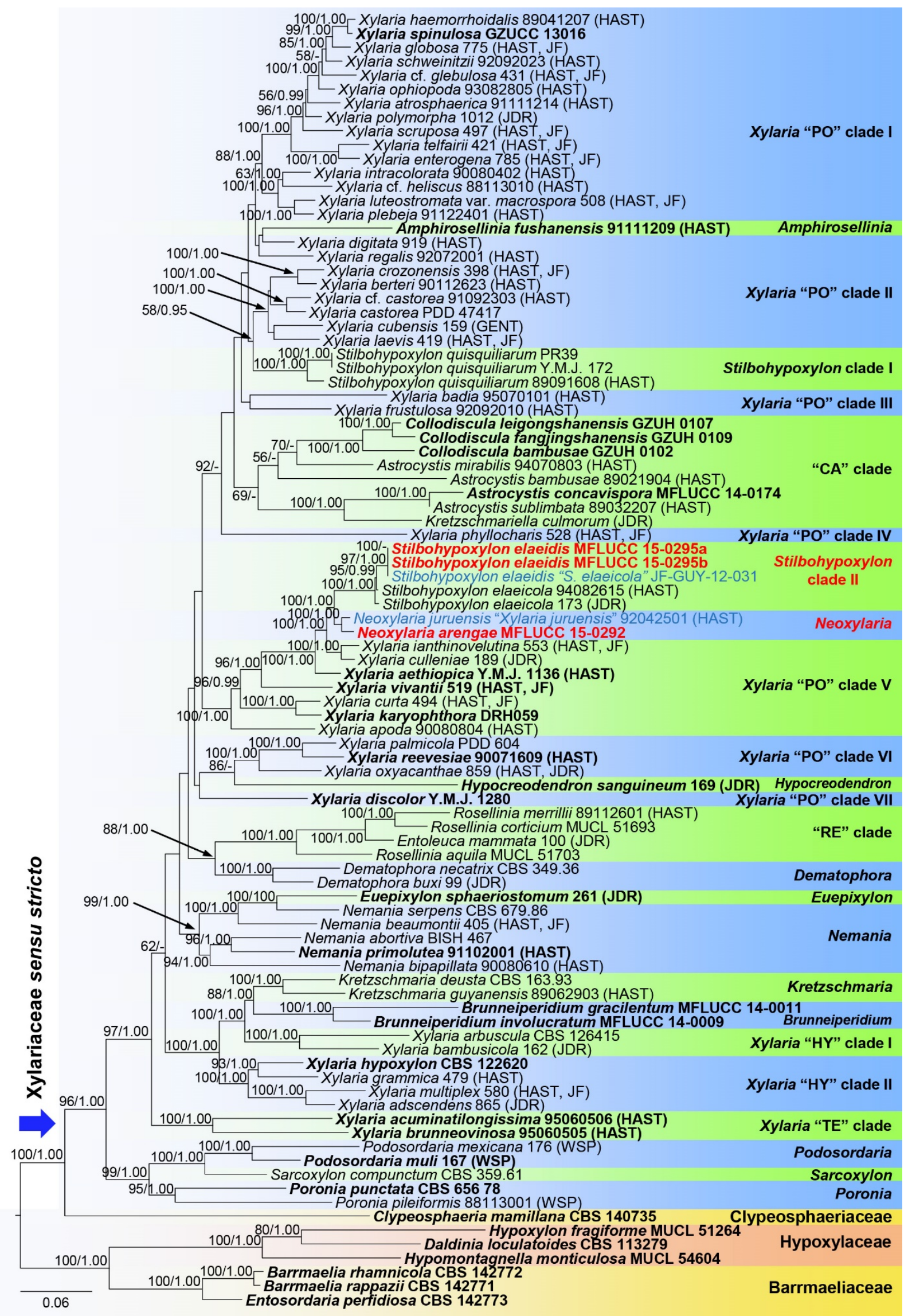

Figure 2 - RAxML tree based on analysis of a combined dataset of ITS-RPB2-TUB2 sequence dataset from selected species of Xylariaceae. Bootstrap support values for maximum likelihood (ML) greater than 50\%, and Bayesian posterior probabilities (BYPP) greater than 0.90 are given at the nodes. Ex-type strains are in bold. Newly generated taxa are in red. The tree is rooted to 
Daldinia loculatoides (CBS 113279), Hypoxylon fragiforme (MUCL 51264), Hypomontagnella monticulosum (MUCL 54604) (Hypoxylaceae), Barrmaelia rappazii (CBS 142771), B. rhamnicola (CBS 142772), and Entosordaria perfidiosa (CBS 142773) (Barrmaeliaceae).

The sexual morph of Xylaria hypoxylon comprises a stroma that is grey to dull black, cylindrical to narrowly fusiform to fan-shaped, with a long persistent white peeling outer layer and ostiolar papillae. The perithecia are immersed, brown to black, with a low conical papilla at center, asci are cylindrical with $\mathrm{J}+$, apical ring, and ascospores are brown ellipsoid-inequilateral with a sinuous germ slit and cellular appendage (Peršoh et al. 2009, Daranagama et al. 2018). The new species collected in this study is clearly different from members of Xylaria sensu stricto based on host preferences and perithecia bulging from the long, but relatively small stromata.

Based on the morpho-molecular differences, we introduce a new genus Neoxylaria to accommodate Neoxylaria arengae. Xylaria culleniae, $X$. ianthinovelutina, $X$. aethiopica and $X$. vivantii (Xylaria "PO" clade V) also clustered with Neoxylaria and these species form conspicuously exposed perithecial contours under a narrowly striped outer layer, which is similar to Neoxylaria. Even though the morphological similarities exist, these species do not form a monophyletic clade. Therefore, we do not treat them under Neoxylaria. Further morpho-molecular studies are essential to clarify their generic boundaries.

Xylaria juruensis and $X$. queenslandica resemble Neoxylaria arengae in having cylindrical or narrowly fusiform, erect stroma, a brown hairy-tomentose stipe, immersed ascoma, cylindrical asci with inverted, hat-shaped, $\mathrm{J}+$, apical ring, and brown ascospores with a straight germ slit which lacks a mucilaginous sheath. Thus, $X$. juruensis and $X$. queenslandica are transferred to Neoxylaria as $N$. juruensis and $N$. queenslandica comb. nov.

Neoxylaria arengae Konta \& K.D. Hyde, sp. nov.

Fig. 3

Index Fungorum number: IF556651; Facesoffungi number: FoF03395

Etymology - Refers to the name of the host genus, Arenga

Holotype - MFLU 15-0267

Saprobic on dead petiole of Arenga pinnata (Arecaceae). Sexual morph: Stromata (1.6-)4$27(-30) \times 0.5-1 \mathrm{~mm}(\bar{x}=13 \times 0.7 \mathrm{~mm}, \mathrm{n}=30)$, erect, coriaceous, solitary, cylindrical, simple to branched from the base, unbranched when immature, branching from the base at maturity with 3(5) branches, arising separately or in small bundles, stipes (stem) (1.7-)2.1-4.6(-7.1) × 0.4-1 mm $(\bar{x}$ $=3.2 \times 0.7 \mathrm{~mm}, \mathrm{n}=20$, up to $12 \mathrm{~mm}$ ), cylindrical, longitudinally, black, with a hairy-tomentose broadened base, smooth to downy to hairy-tomentose above; tomentum black to dark brown, fertile part (1.7-)2.5-18(-25) mm $(\bar{x}=9 \mathrm{~mm}, \mathrm{n}=20)$, bearing 29 to 35(-45) exposed perithecia, apex sterile, rarely find finely longitudinally furrowed delimiting narrow stripes, roughened with prominent ostiolar papillae, perithecia scattered along the stroma, arranged in a zigzag or in straight rows, without circumferential wrinkles isolating groups of perithecia, perithecial contours most often conspicuous, visible as black single or small fusiform ascoma, surface, outer crust, thick, coriaceous, cracked, interior solid, brown with white tissue surrounding perithecial layer, sterile apex attenuated conical, up to 1-2(-3) mm. Perithecia 400-620 × 260-570 $\mu \mathrm{m}(\bar{x}=493 \times 464 \mu \mathrm{m}$, $\mathrm{n}=10$ ), pale brown, immersed in stromatic tissues, globose to subglobose, ostiolate, papillate, slightly conspicuous, with periphyses. Peridium $80-130 \mu \mathrm{m}$ wide $(\bar{x}=100 \mu \mathrm{m}, \mathrm{n}=20)$, thickwalled, composed of several layers, outwardly, thick-walled, comprising dark brown cells of textura angularis and inwardly, thick-walled, comprising hyaline to pale brown cells of textura prismatica. Ostiole 150-215 $\times 150-285 \mu \mathrm{m}(\bar{x}=180 \times 210 \mu \mathrm{m}, \mathrm{n}=5)$, raised-discoid, brown to black surrounding disc appear on the surface; hyaline, papillate, with a central periphyses. Paraphyses 3-5(-7) $\mu \mathrm{m}$ wide $(\bar{x}=4 \mu \mathrm{m}, \mathrm{n}=10)$, filamentous, cylindrical, septate, unbranched. Asci 74-160 $(-180) \times 5-12 \mu \mathrm{m}(\bar{x}=115 \times 7 \mu \mathrm{m}, \mathrm{n}=20), 6-8$-spored, unitunicate, cylindrical, long pedicellate, apically rounded, with a $\mathrm{J}+$, apical ring, inverted hat-shaped. Ascospores 10-18(-22) $\times$ 3.5-6(-7.5) $\mu \mathrm{m}(\bar{x}=15 \times 5 \mu \mathrm{m}, \mathrm{n}=20)$, uniseriate, hyaline to pale brown when immature, dark brown at maturity, broad fusoid, unicellular, a lot of small guttules when immature, two large 
guttules at maturity, smooth-walled, with a straight, full length germ slit. Asexual morph: Undetermined. Appressoria 4-9 $\times 3-10 \mu \mathrm{m}(\bar{x}=6 \times 6 \mu \mathrm{m}, \mathrm{n}=20)$, solitary, hyaline, mostly globose, irregular in shape, thick-walled.

Culture characteristics - Ascospores germinated on MEA within 24 hours and germ tube was produced from germ slit. Mycelium immersed in the medium, septate, branched, and smoothwalled hyphae. Colonies on MEA, medium dense, irregular in shape, flowered-like, surface slightly rough with curled margin, radiating outward colony, flat, slightly raised at the centre, hairy fluffy, initially white, becoming white at the margin, greyish white near the centre, with black and white curled, radiated near the centre; reverse zonate, yellow and white, curled with black radiating outward colony; not produced pigmentation on medium.

Material examined - THAILAND, Phang-nga Province, on dead petiole of Arenga pinnata (Wurmb) Merr. (Arecaceae), 5 December 2014, S. Konta, PHR03d (MFLU 15-0267, holotype; KUN-HKAS 100698, isotype), ex-type living culture, MFLUCC 15-0292.

Notes - Neoxylaria arengae resembles $N$. (syn. Xylaria) juruensis, but it has shorter stromata (fertile part) (1.6-)4-27(-30) mm vs 15-40 mm), forms branches at the base, smaller perithecia (0.4-0.6 diam. mm vs 0.7-0.9 diam. mm), slightly larger in asci (74-160 × 5-12 $\mu \mathrm{m}$ vs 100-120 $\times$ 4-6 $\mu \mathrm{m})$ and ascospores overlapping in size $(10-18(-22) \times 3.5-6(-7.5) \mu \mathrm{m}$ vs $12-17 \times 4-5 \mu \mathrm{m})$. However, $N$. arengae was found on a dead part of Arenga pinnata, while $N$. juruensis was reported from a rotten palm frond and on Arenga engleri (Arecaceae) (Hennings 1904, Hsieh et al. 2010, Becerril-Navarrete et al. 2018).

Xylaria queenslandica is similar to Neoxylaria and is transferred in this paper. Neoxylaria arengae is similar to $X$. tucumanensis in the appearance of the stromata, but our new species has larger stromata $(4-27 \times 0.5-1$ vs $12-15 \times 0.5-0.6 \mathrm{~mm})$, shorter stipes $(2.1-4.6 \times 0.4-1$ vs $6-7 \times$ $0.2-0.3 \mathrm{~mm}$ ), forming 3(-5) branches at base, while $X$. tucumanensis form simple (unbranched), and larger numbers of perithecia (bearing 29-35 vs 9-17 perithecia per stroma) (Hladki \& Romero 2010). Neoxylaria arengae also shares similar stomatal characters with $X$. diminuta, $X$. enteroleuca, $X$. filiformioidea, $X$. himalayensis, $X$. mellissi, and $X$. subgracillima, but differs in having branches at the base, of longer stromata (fertile part), and more perithecia per stromata than other species (Cooke 1883, Hennings 1904, Martin 1970, Narula et al. 1985, Hladki \& Romero 2010, Huang et al. 2014). We also cross checked with $X$. diminuta, $X$. enteroleuca, $X$. filiformioidea, $X$. himalayensis, $X$. mellissi and $X$. subgracillima, but only $X$. enteroleuca has DNA sequence data, thus, we included $X$. enteroleuca in the phylogenic tree (not shown) and found that it did not form a branch close to Stilbohypoxyon or Neoxylaria.

Neoxylaria juruensis (Henn.) Konta \& K.D. Hyde, comb. nov.

Index Fungorum number: IF556652; Facesoffungi number: FoF06240

三 Xylaria juruensis Henn., Hedwigia 43(4): 262 (1904)

Notes - Xylaria juruensis was introduced by Hennings (1904) from decayed palm material collected in Brazil. It similar to Neoxylaria arengae in having erect stromata, with prominent perithecia and a sterile apex. There is no sequence data for the type of Xylaria juruensis, but there is for a putatively named collection (92042501 HAST) from Taiwan (Hsieh et al. 2010). In the phylogenetic tree, the strain from Taiwan clustered together with $N$. arenage with strong support (100\% ML, 1.00 BYPP, Fig. 2) and maybe the same genus, but is unlikely to be Xylaria juruensis sensu stricto, because of its location.

Neoxylaria queenslandica (Joanne E. Taylor, K.D. Hyde \& E.B.G. Jones) Konta \& K.D. Hyde, comb. nov.

Index Fungorum number: IF557765; Facesoffungi number: FoF08464

三 Xylaria queenslandica Joanne E. Taylor, K.D. Hyde \& E.B.G. Jones, in Taylor \& Hyde, Fungal Diversity Res. Ser. 12: 236 (2003)

Notes - Xylaria queenslandica was also collected from a palm (Archontophoenix alexandrae) in Australia and is very similar to Neoxylaria arengae (Taylor \& Hyde 2003). Xylaria 
queenslandica differs from $N$. arengae in its average ascospore size $(13 \times 4.7$ vs $10-18(-22) \times 3.5-$ 6(-7.5) $\mu \mathrm{m}$ ) and mid red brown versus dark brown mature ascospores (Taylor \& Hyde 2003).

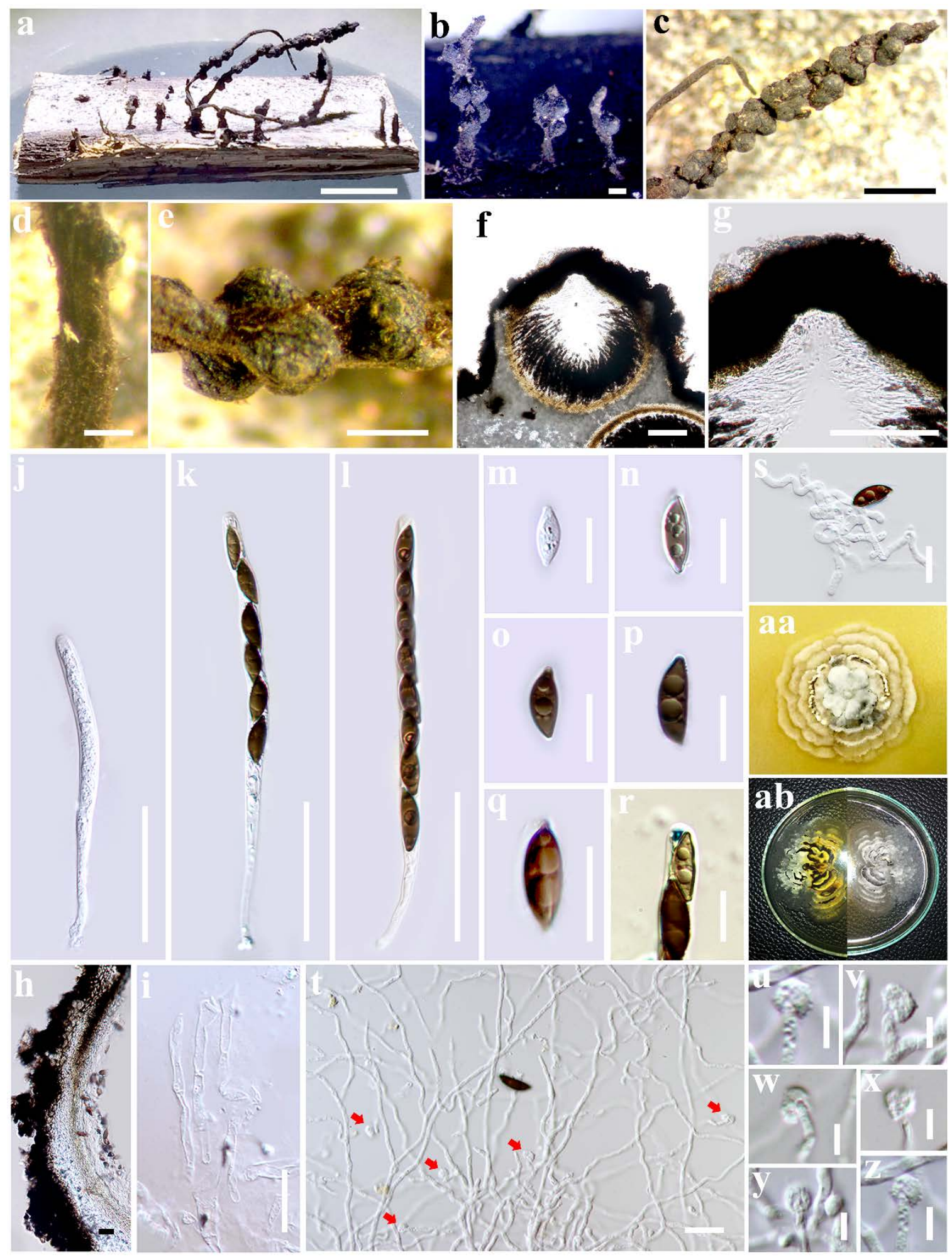

Figure 3 - Neoxylaria arengae (MFLU 15-0267, holotype). a-b Stromata on host substrate. c, e Perithecia and sterile apex strongly conical. d Stem with brown hair (Pubescent). f Section of a stroma. g Periphyses. h Peridium. i Paraphyses. j-l Asci. m-p Ascospores. q Ascospore with germ slit. r J+, apical ring in Melzer's reagent. s Germinated ascospore. t Germinated ascospore with appressoria-like structures. $\mathrm{u}-\mathrm{z}$ Appressoria-like structures. aa, ab Colony on MEA. Scale Bars: $\mathrm{a}=$ $5 \mathrm{~mm}, \mathrm{~b}, \mathrm{~d}, \mathrm{e}=0.5 \mathrm{~mm}, \mathrm{c}=2 \mathrm{~mm}, \mathrm{f}, \mathrm{g}=0.1 \mathrm{~mm}, \mathrm{~h}, \mathrm{i}, \mathrm{t}=20 \mu \mathrm{m}, \mathrm{j}-\mathrm{l}=50 \mu \mathrm{m}, \mathrm{m}-\mathrm{s}=10 \mu \mathrm{m}, \mathrm{u}-\mathrm{z}=$ $5 \mu \mathrm{m}$. 
Stilbohypoxylon Henn., Hedwigia 41: 16 (1902)

Index Fungorum number: IF5264; Facesoffungi number: FoF06306

Saprobic on various hosts in tropical and subtropical regions. Sexual morph: Stromata superficial, carbonaceous perithecia, solitary to gregarious, lining in row or in groups, dark brown to black, smooth or rugulose or with cracks or warts or minute furrows, with or without conical to acicular synnematal remnants borne on mature stromata. Ascomata globose to pulvinate, ampulliform or mammiform, black carbonaceous, brittle, fragile, ostiolate, papillate, encircled with vaguely flattened area. Synnemata borne laterally on mature stromata or directly on wood, acicular to conical to somewhat cylindrical, light-brown or black, carbonaceous, brittle, fragile, sometimes covered by green-grey conidiophores at the base, or covered by yellow, greenish-yellow, or ochraceous scales, powdery or hyphae-like at early state. Paraphyses hyaline, filamentous, cylindrical, septate, unbranched, longer than asci. Asci 8-spored, unitunicate, cylindrical, pedicellate, apically rounded, with a $\mathrm{J}+$, inverted hat-shaped, apical ring. Ascospores uniseriate, hyaline to pale brown when immature, dark brown at maturity, ellipsoidal to broad-fusoid, unicellular, with two large guttules, smooth-walled, with a straight germ slit over the whole spore length, surrounded by a thin mucilaginous sheath, with a pad of denser mucilage at each apex. Asexual morph: Hyphomycetous, geniculosporium-like. Synnemata green, scattered, acicular to conical, cylindrical, branched or unbranched. Conidiophores dense, dark brown palisades dichotomously branched several times from the bases. Conidiogenous cells terminal, cylindrical, hyaline, smooth, bearing lateral and terminal denticulate conidial secession scars. Conidia produced holoblastically in sympodial sequence, hyaline to pale yellow, yellowish to pale olivaceous, smooth, obovate, with a truncate base (adapted from Rogers \& Ju 1997, Daranagama et al. 2018).

Type species - Stilbohypoxylon moelleri Henn.

Notes - Stilbohypoxylon contains 11 species, viz. S. elaeidicola, S. hypoxylinum, S. ignobile, S. immundum, S. macrosporum, S. minus, S. moelleri (type), S. novae-zelandiae, S. quisquiliarum, S. samuelsii and S. theissenii (Hyde et al. 2020, Index Fungorum 2020). All taxa are characterized by superficial, globose (sphaerical) stromata, with a smooth or delicately wrinkled surface that is usually overlain with yellow, greenish yellow or ochraceous scales at an early stage, unitunicate asci, unicellular ascospores with a straight germ slit, with or without mucilaginous sheath and a pad of denser mucilage at each end (Rogers \& Ju 1997, Fröhlich \& Hyde 2000, Hladki \& Romero 2003, Petrini 2004, Daranagama et al. 2018).

According to Hsieh et al. (2010), Li et al. (2017), Daranagama et al. (2018) and Wendt et al. (2018), Stilbohypoxylon species clusters with Xylaria species in two subclades and it was mentioned that Stilbohypoxylon is polyphyletic. Currently, only S. elaeidicola and S. quisquiliarum have sequence data, while the generic type of Stilbohypoxylon (S. moelleri) has not yet been sequenced. Therefore, the phylogenetic affinity of Stilbohypoxylon is uncertain.

A lot of clumping has previously occurred in defining Stilbohypoxylon species (Fröhlich \& Hyde 2000). Rogers \& Ju (1997) revisited the genus and designated an epitype for the type species, S. moelleri, which was collected from a palm, Euterpe sp., in South America. We therefore follow Rogers \& Ju (1997) and place the recent collections from palms in Stilbohypoxylon sensu stricto. Stilbohypoxylon quisquiliarum was collected in French Guiana on "wood" (Montagne 1840) and described in Miller (1961). Rogers \& Ju (1997) have described the asexual morph of $S$. quisquiliarum and illustrated the ascospores with a spiral germ slit from an isotype specimen, which differentiates it from Stilbohypoxylon sensu stricto. Stilbohypoxylon quisquiliarum does not group with the clade comprising S. elaeidis and S. elaeidicola (Stilbohypoxylon clade II, Fig. 2). Therefore, we leave S. quisquiliarum as Stilbohypoxylon sensu lato (Stilbohypoxylon clade I, Fig. 2) until it is epitypified and described as a new genus. Unfortunately, the epitype specimen of $S$. moelleri has not yet been sequenced. Therefore, the congeneric status of the representative species (S. elaeidis and S. elaeidicola) with S. moelleri and the phylogenetic status of Stilbohypoxylon sensu stricto still need to be proven, however they all occur on decaying palm material.

The type species of Stilbohypoxylon, S. moelleri was detailed in Rogers \& Ju (1997) and its lectotype was observed by Daranagama et al. (2018). Stilbohypoxylon moelleri is characterized by 
sphaerical, gregarious, black, carbonaceous, fragile stromata, bearing 1-3-conical to acicular synnemata, cylindrical asci with apical ring bluing in Melzer's reagent, brown to dark brown ascospores and a geniculosporium-like asexual morph (Rogers \& Ju 1997, Daranagama et al. 2018). A comparison of $S$. moelleri and $S$. elaeidis shows that $S$. elaeidis has solitary stroma with a smooth surface and lack of synnemata on stromata surface.

Stilbohypoxylon elaeidis Konta \& K.D. Hyde, sp. nov.

Fig. 4

Index Fungorum number: IF558007; Facesoffungi number: FoF05123

Etymology - Refers to the name of the host genus, Elaeis

Holotype - MFLU 15-0270

Saprobic on dead petiole of Elaeis guineensis (Arecaceae). Sexual morph: Stromata superficial, visible as a black conical, or globose on the top view of host surface, solitary, or in groups, bearing conical to acicular synnematal remnants on mature stromata, carbonaceous, brittle, fragile, curved to straight. Ascomata 440-730 × 360-660 $\mu \mathrm{m}(\bar{x}=565 \times 530 \mu \mathrm{m}, \mathrm{n}=25)$, black, carbonaceous, brittle, conical to mammiform, 1 per stroma, glabrous, covered with remnants of host tissue, disappearing at maturity, with indistinct ostiolate. Synnemata 250-470 $\mu \mathrm{m}(\bar{x}=340 \mu \mathrm{m}$, $\mathrm{n}=10$ ), solitary, covered with yellow hyphae-like when immature, spine-like, wide at the base narrow towards the apex, black. Peridium 65-120(-130) $\mu \mathrm{m}$ wide $(\bar{x}=90 \mu \mathrm{m}, \mathrm{n}=25)$, thickwalled, composed of several layers, outwardly comprising dark brown to black cells $2-4 \mu \mathrm{m}$, of textura angularis. Paraphyses 2.3-3.7 $\mu \mathrm{m}$ wide $(\bar{x}=3 \mu \mathrm{m}, \mathrm{n}=20)$, filamentous, cylindrical, septate, unbranched, longer than asci. Asci 113-136 × 7-12 $\mu \mathrm{m}(\bar{x}=125 \times 9 \mu \mathrm{m}, \mathrm{n}=20)$, 6-8spored, unitunicate, cylindrical, long pedicellate, apically rounded, with a $\mathrm{J}+$, inverted, hat-shaped apical ring, $2-5 \times 2-3 \mu \mathrm{m}(\bar{x}=5 \times 2 \mu \mathrm{m}, \mathrm{n}=10)$. Ascospores 13-21 $\times 5-8 \mu \mathrm{m}(\bar{x}=17 \times 6 \mu \mathrm{m}, \mathrm{n}=$ 30), uniseriate, hyaline to pale brown when immature, dark brown at maturity, equilateral ellipsoidal to broadly fusoid, unicellular, with two large guttules, smooth-walled, with a straight germ slit over the whole spore length, surrounded by thin mucilaginous sheath, with a pad of denser mucilage at each apex. Asexual morph: Undetermined.

Culture characteristics - Ascospores germinated on MEA within 24 hours and germ tube produced from germ slit. Mycelium immersed in media, mycelium at the center appears as grey to dark-green, mycelium towards margin appears white, hyphae, septate, branched, and smooth. Colonies on MEA, medium dense, irregular in shape, flowered-like, surface slightly rough with curled and undulate edge, radiating outward colony, flat, slightly raised at the centre, felty to cotonny, azonate, white at the margin, grey to dark grey near the centre, with black curled radiating towards the centre; reverse yellowish, curled with black radiating towards the centre; not produced pigmentation on medium.

Material examined - THAILAND, Krabi Province, on a dead petiole of Elaeis guineensis Jacq. (Arecaceae), 3 December 2014, S. Konta, KBF01a (MFLU 15-0270, holotype), ex-type living cultures, MFLUCC 15-0295a, MFLUCC 15-0295b.

Addition sequence data - LSU: MT496755, SSU: MT495460, TEF: MT495461 (MFLUCC 15-0295a); LSU: MT496756, SSU: MT495461 (MFLUCC 15-0295b).

Notes - Stilbohypoxylon elaeidis is closely related to S. elaeidicola and both species are from palms. They form a well-separated branch with high statistical support in the combined ITS-RPB2TUB2 phylogenetic analysis (Fig. 2). A comparison of ITS, RPB2 and TUB2 sequence data including gaps shows that S. elaeidis differs from S. elaeidicola (strains Y.M.J. 173 and 94082615 HAST) in 6 bp and 4 bp (1\% and $0.68 \%$ of nucleotide base) for ITS; 7 bp and 3 bp (0.6\% and $0.26 \%$ of nucleotide base) for RPB2; 53 bp and 42 bp (3.35\% and 2.6\% of nucleotide base) for TUB2. Furthermore, phylogenetic analysis showed that $S$. elaeidis clusters with S. elaeidicola strain JF-GUY-12-031 with good bootstrap support (97\% ML, 1.00 BYPP, Fig. 2). However, this strain has no morphological description and only ITS sequence is available in GenBank database. Therefore, we rename this strain as S. elaeidis. Morphological comparison of Stilbohypoxylon species are detailed in Table 3. 


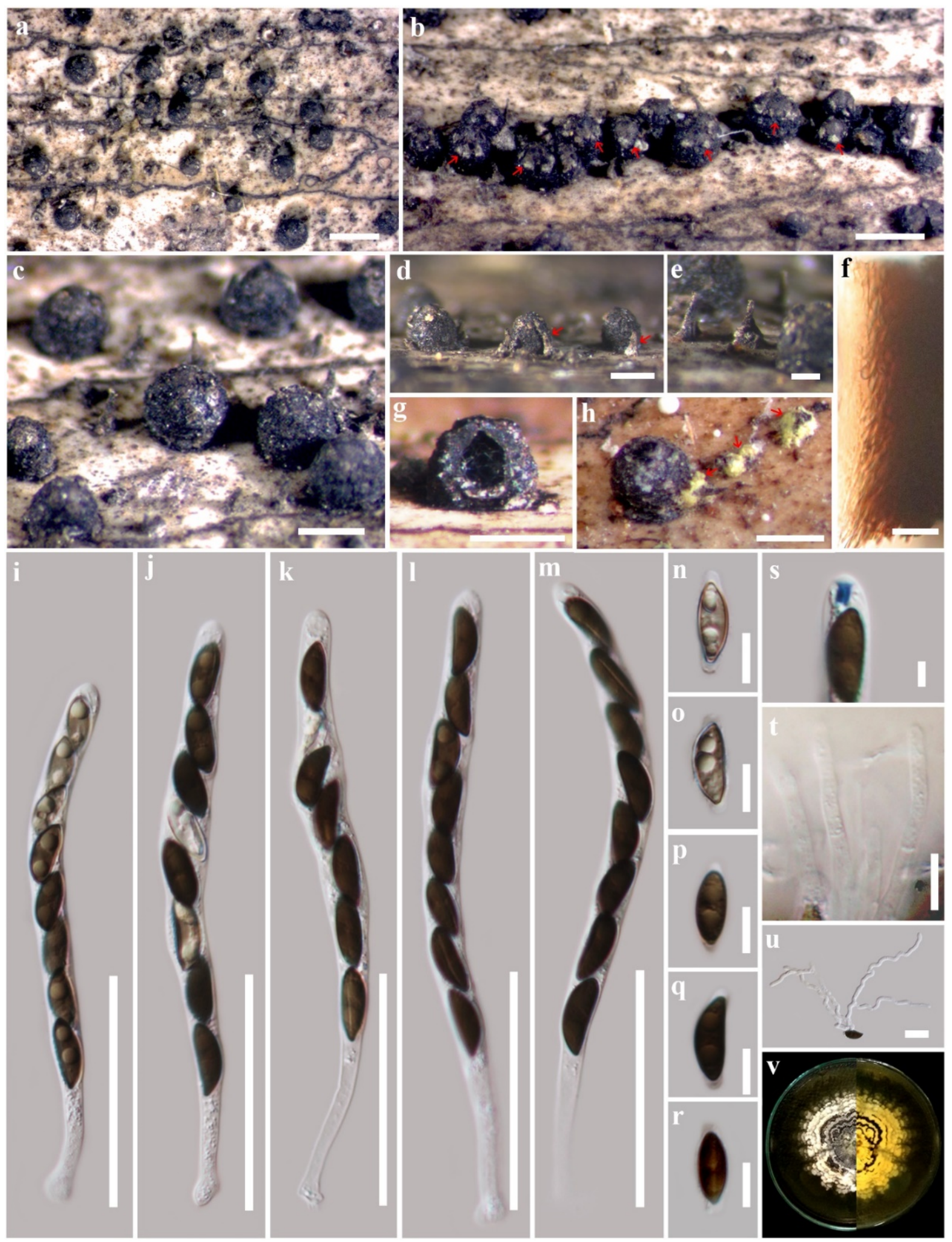

Figure 4 - Stilbohypoxylon elaeidis (MFLU 15-0270, holotype). a Immature and mature stromata on the host substrate from above. b Immature stromata covered with remnants of host material. c Close up of mature stromata. d Synnematal remnants. e Close up of synnematal remnants. $\mathrm{f}$ Peridium. g Section of stromata showing the perithecia. h Synnematal remnants covered by yellow hyphae-like. i-k Immature asci. l-m Mature asci. n, o Immature ascospores. p, q Mature ascospores. $\mathrm{r}$ Ascospore with germ slit. s J+, apical ring in Melzer's reagent. t Paraphyses. $\mathrm{u}$ Germinated ascospore. v Colony on MEA from above and below. Scale Bars: $\mathrm{a}, \mathrm{b}=1000 \mu \mathrm{m}$, $\mathrm{c}, \mathrm{d}, \mathrm{g}, \mathrm{h}=500 \mu \mathrm{m}, \mathrm{e}=200 \mu \mathrm{m}, \mathrm{f}, \mathrm{n}-\mathrm{t}=10 \mu \mathrm{m}, \mathrm{i}-\mathrm{m}=50 \mu \mathrm{m}, \mathrm{u}=20 \mu \mathrm{m}$. 
Table 3 Morphological comparison of species of Stilbohypoxylon.

\begin{tabular}{|c|c|c|c|c|c|c|c|}
\hline Taxa & $\begin{array}{l}\text { Stromata } \\
(\mu \mathrm{m})\end{array}$ & $\begin{array}{l}\text { Synnemata } \\
(\mu \mathrm{m})\end{array}$ & $\begin{array}{l}\text { Peridium } \\
(\mu \mathrm{m})\end{array}$ & $\begin{array}{l}\text { Asci } \\
(\mu \mathrm{m})\end{array}$ & $\begin{array}{l}\text { Apical ring } \\
(\mu \mathrm{m})\end{array}$ & $\begin{array}{l}\text { Ascospores } \\
(\mu \mathrm{m})\end{array}$ & References \\
\hline $\begin{array}{l}\text { Stilbohypoxylon } \\
\text { elaeidicola }\end{array}$ & $\begin{array}{l}(550-) 813 \pm 110(-1125) \text { diam. } \times \\
(400-) 605 \pm 80(-825) \text { high, rough, } \\
\text { rugose surface, sometimes with } \\
\text { cracks, dull or shiny, sometimes } \\
\text { covered by host material, } \\
\text { sometimes } 2-3 \text { fused together }\end{array}$ & $\begin{array}{l}\text { Up to } 550 \\
\text { high }\end{array}$ & $50-75$ & $\begin{array}{l}11-16 \times \\
105-130\end{array}$ & $\begin{array}{l}\text { Upper } 3-4 \text {, } \\
\text { lower } 2-3 \times \\
2-4 \text { high }\end{array}$ & $\begin{array}{l}(6-) 7 \pm 0.5(-8.5) \text { diam. } \times \\
(13-) 16 \pm 1.5(-22) \text { high, } \\
\text { straight germ slit, slimy } \\
\text { cap at each end and on the } \\
\text { flat side }\end{array}$ & $\begin{array}{l}\text { Hennings 1895, } \\
\text { Petrini } 2004\end{array}$ \\
\hline S. elaeidis & $\begin{array}{l}367-664 \text { diam. } \times 440-730 \text { high }(\bar{x}= \\
527 \times 565) \text {, globose, smooth, with } \\
\text { cracks of the host on the surface, } \\
\text { solitary, } 1 \text { ascoma per stroma, } \\
\text { surrounded by synnematal remnants } \\
\text { on host substrate }\end{array}$ & $\begin{array}{l}253-470 \\
\text { high, covered } \\
\text { by yellow } \\
\text { hyphae-like at } \\
\text { early stage }\end{array}$ & $\begin{array}{l}65-120(- \\
130), \\
\text { composed of } \\
\text { textura } \\
\text { angularis }\end{array}$ & $\begin{array}{l}7-12 \times \\
113-136\end{array}$ & $\begin{array}{l}2-3 \times 2-5 \\
\text { high }\end{array}$ & $\begin{array}{l}\text { 5-8 diam. } \times 13-21 \text { high }(\bar{x} \\
=6 \times 17, \mathrm{n}=30) \text { straight } \\
\text { germ slit, thin } \\
\text { mucilaginous sheath, with } \\
\text { a pad mucilage at each } \\
\text { apex }\end{array}$ & This study \\
\hline S. hypoxylinum & $\begin{array}{l}\text { 375-450 wide } \times 450-700 \text { high, } \\
\text { globose to ampulliform, dull, } \\
\text { powdery covered on stromata, } \\
\text { solitary, synnemata }\end{array}$ & - & 25 & - & $\begin{array}{l}\text { Upper 4-4.5, } \\
\text { lower 3.5-4.5 } \\
\times 4-4.5 \text { high }\end{array}$ & $\begin{array}{l}(6.5-) 8 \pm 0.8(-9) \text { diam. } \times \\
(14-) 17 \pm 1.5(-21) \text { high, } \\
\text { straight germ slit }\end{array}$ & Petrini 2004 \\
\hline S. ignobile & $\begin{array}{l}625-800 \text { wide } \times 750-925 \text { high, } \\
\text { cupulate with an elongate broad } \\
\text { base, with cracks and warts on the } \\
\text { surface, singly or } 2-4 \text { fused } \\
\text { together, crowded, touching each } \\
\text { other }\end{array}$ & - & $25-50$ & - & - & $\begin{array}{l}\text { 4.5-5 diam. } \times 9-10.5 \text { high } \\
(\mathrm{n}=3), \text { straight germ slit }\end{array}$ & Petrini 2004 \\
\hline S. immundum & $\begin{array}{l}(625-) 920 \pm 190(-1250) \text { diam. } \times \\
(625-) 930 \pm 175(-1300) \text { high, } \\
\text { globose, subglobose, obovate to } \\
\text { cupulate, surface warty, cylindrical } \\
\text { synnemata, crowded, with } \\
\text { perithecia closely adherent }\end{array}$ & - & Up to 125 & - & $\begin{array}{l}\text { Upper 4-7, } \\
\text { lower } 3.5-6 \\
\times 6-11 \text { high }\end{array}$ & $\begin{array}{l}(8.5-) 11 \pm 1.5(-14) \text { diam. } \\
\times(27-) 32 \pm 3(-39) \text { high, } \\
\text { straight, rarely oblique } \\
\text { germ slit }\end{array}$ & Petrini 2004 \\
\hline $\begin{array}{l}\text { S. } \\
\text { macrosporum }\end{array}$ & $\begin{array}{l}600-900 \text { diam., globose or semi- } \\
\text { globose, smooth, solitary or slightly } \\
\text { fusionate, gregarious, with } 1-2 \\
\text { synnemata on mature stromata, } \\
\text { verrucose to rugulose }\end{array}$ & 400-500 high & - & $\begin{array}{l}9-12 \times \\
200-260\end{array}$ & $\begin{array}{l}6.5 \times 8- \\
10.5 \text { high }\end{array}$ & $\begin{array}{l}\text { 12-13 diam. } \times 30-40 \text { high, } \\
\text { spiral germ slit }\end{array}$ & $\begin{array}{l}\text { Hladki \& } \\
\text { Romero 2003, } \\
\text { Daranagama et } \\
\text { al. } 2018\end{array}$ \\
\hline
\end{tabular}


Table 3 Continued.

\begin{tabular}{|c|c|c|c|c|c|c|c|}
\hline Taxa & $\begin{array}{l}\text { Stromata } \\
(\mu \mathrm{m})\end{array}$ & $\begin{array}{l}\text { Synnemata } \\
(\mu \mathrm{m})\end{array}$ & $\begin{array}{l}\text { Peridium } \\
(\mu \mathrm{m})\end{array}$ & $\begin{array}{l}\text { Asci } \\
(\mu \mathrm{m})\end{array}$ & $\begin{array}{l}\text { Apical ring } \\
(\mu \mathrm{m})\end{array}$ & $\begin{array}{l}\text { Ascospores } \\
(\mu \mathrm{m})\end{array}$ & References \\
\hline S. minus & $\begin{array}{l}400-600 \text { diam., perithecioid, } \\
\text { globose, rarely fusionate, } \\
\text { gregarious, with } 1 \text { small synnema } \\
\text { on immature stromata, shining, } \\
\text { furfuraceous }\end{array}$ & 100-200 high & - & $\begin{array}{l}13-14.5 \\
\times 165- \\
185\end{array}$ & $\begin{array}{l}6.5-7.8 \times \\
5-6.5\end{array}$ & $\begin{array}{l}12-13 \times 23.5-26(-27.5), \\
\text { straight germ slit }\end{array}$ & $\begin{array}{l}\text { Hladki \& } \\
\text { Romero } 2003\end{array}$ \\
\hline $\begin{array}{l}\text { S. moelleri } \\
\text { (type species) }\end{array}$ & $\begin{array}{l}\text { 600-1000 diam., rough, overlain } \\
\text { with yellow to greenish yellow } \\
\text { scales at early stage, texture brittle }\end{array}$ & 200-800 high & - & $\begin{array}{l}8-10 \times \\
60-220\end{array}$ & $\begin{array}{l}2.5-3.5 \times \\
3-5\end{array}$ & $\begin{array}{l}6-8 \times 14.5-17 \text {, straight } \\
\text { germ slit, enclosed by a } \\
\text { thin hyaline sheath }\end{array}$ & $\begin{array}{l}\text { Rogers \& Ju } \\
\text { 1997, } \\
\text { Daranagama et } \\
\text { al. } 2018\end{array}$ \\
\hline $\begin{array}{l}\text { S. novae- } \\
\text { zelandiae }\end{array}$ & $\begin{array}{l}(400-) 553 \pm 82(-775) \text { diam. } \times \\
(350-) 485 \pm 70(-700) \text { high, } \\
\text { globose to subglobose, cupulate, } \\
\text { rugose, with small cracks, solitary } \\
\text { or densely crowded }\end{array}$ & - & $\geq 25$ & - & $\begin{array}{l}\text { Upper } 2.4- \\
3.8, \text { lower } \\
1.9-2.8 \times \\
(1.9-) 2.3 \pm \\
0.4(-3.3)\end{array}$ & $\begin{array}{l}(5.8-) 6.7(-8.2) \times(9.6- \\
) 15.3(-18.2) \text { often with } \\
\text { one cellular appendage, } \\
\text { surrounded by a slimy } \\
\text { sheath, sigmoid or straight } \\
\text { germ slit }\end{array}$ & Petrini 2003 \\
\hline $\begin{array}{l}\text { S. } \\
\text { quisquiliarum }\end{array}$ & $\begin{array}{l}\text { (600-)1020 } \pm 265(-1500) \text { diam. } \times \\
(575-) 955(-1600) \text { high, globose to } \\
\text { subglobose, ovoid, covered by } \\
\text { yellow scales when young, later } \\
\text { turning brown, surface warty, } \\
\text { powdery, cracks, crowded, } \\
\text { solitaryto } 9 \text { fused together with } 1 \\
\text { synnemata on immature stromata }\end{array}$ & - & Up to 75 & - & $\begin{array}{l}\text { Upper 5-8, } \\
\text { lower } 4-7 \times \\
6-10\end{array}$ & $\begin{array}{l}(10-) 13(-16) \times(23-) 28(- \\
\text { 34), sigmoid to spiral germ } \\
\text { slit }\end{array}$ & $\begin{array}{l}\text { Rogers \& Ju } \\
\text { 1997, Esteban et } \\
\text { al. 2013, } \\
\text { Daranagama et } \\
\text { al. } 2018\end{array}$ \\
\hline S. samuelsii & $\begin{array}{l}\text { 700-1200 diam., spherical, } \\
\text { gregarious, conical to acicular } \\
\text { synnematal remnant, rugulose, } \\
\text { sometimes overlain with } \\
\text { ochraceous scales, texture hard }\end{array}$ & 200-400 high & & $\begin{array}{l}12-15.5 \\
\times 235- \\
285(- \\
315)\end{array}$ & $\begin{array}{l}5.5-7 \times 8- \\
13\end{array}$ & $\begin{array}{l}\text { 8.5-11(-13) } \times(27-) 30- \\
36(-40), \text { straight germ slit }\end{array}$ & $\begin{array}{l}\text { Rogers \& Ju } \\
\text { 1997, Petrini } \\
2004\end{array}$ \\
\hline S. theissenii & $\begin{array}{l}750-1000 \text { diam. } \times 750-1000 \text { high, } \\
\text { globose, subglobose, with a dull, } \\
\text { rugose surface covered with fine } \\
\text { cracks, conical synnemata }\end{array}$ & - & $25-50$ & - & $\begin{array}{l}\text { Upper 4- } \\
5.5 \text {, lower } \\
3-5 \times 6-7\end{array}$ & $\begin{array}{l}(7-) 8.5(-11) \times(22-) 27(- \\
\text { 33), large subglobose } \\
\text { cellular appendage, straight } \\
\text { to oblique germ slit }\end{array}$ & Petrini 2004 \\
\hline
\end{tabular}


Stilbohypoxylon elaeidicola (Henn.) L.E. Petrini ]as ‘elaeicola’', Sydowia 56(1): 55 (2004).

Index Fungorum number: IF631505; Facesoffungi number: FoF08465

$\equiv$ Rosellinia elaeidicola Henn. [as ‘elaeicola’], Bot. Jb. 22: 77 (1895)

Notes - In our phylogenetic analysis based on DNA sequencedata from ITS region (data not shown) and combined sequence data of ITS, RPB2 and TUB2, Stilbohypoxylon elaeidicola clustered with S. elaeidis with high statistical support (Fig. 2). A comparison of S. elaeidicola with S. elaeidis shows they are different; S. elaeidis has solitary stromata $(440-730 \times 360-660 \mu \mathrm{m})$ with a smooth surface and forms synnemata remnants on the host, and covered the stroma when mature. Stilbohypoxylon elaeidicola has larger stromata (550-1,125 $\times 400-825 \mu \mathrm{m}$ high), single or fused in clusters of 2-3, with rough to rugose walls, and with synnemata on the substrate or the stroma; while in S. elaeidicola asci and ascospores overlap in size with those of S. elaeidis (asci 105-130 $\times$ 11-16 $\mu \mathrm{m}$ vs $113-136 \times 7-12 \mu \mathrm{m}$; ascospores $13-17 \times 7-9 \mu \mathrm{m}$ vs $13-21 \times 5-8 \mu \mathrm{m})$ (Hennings 1895, Petrini 2004).

\section{Discussion}

There have been several taxonomic revisions of the larger Xylariaceae (sensu Daranagama et al. 2016) using traditional morphological concepts (e.g. Jaklitsch \& Voglmayr 2012, Daranagama et al. 2015, Wendt et al. 2018, Lambert et al. 2019). In this paper, we introduce Neoxylaria which has a discrete morphology and is also phylogenetically distinct from Xylaria sensu stricto. Xylarialike taxa have generally been lumped in a single genus pending an upcoming monograph (Stadler et al. pers. comm) and species/genera resolution has not advanced for numerous years. It is clear from the phylogenies generated in different studies (Hsieh et al. 2009, U'Ren et al. 2016, Daranagama et al. 2018, Wendt et al. 2018), that Xylaria is not monophyletic and should be spilt into several distinct genera. Xylaria hypoxylon, the type species is well-resolved and morphologically and phylogenetically characterized (Peršoh et al. 2009). Hsieh et al. (2010) and U’Ren et al. (2016) showed that there are three major Xylaria clades: Xylaria species associated with termite nests "TE clade" (including X. nigripes), X. hypoxylon (Xylaria sensu stricto) and closely related species "HY clade" and $X$. polymorpha and closely related species "PO clade”. Several other xylaria-like species also cluster in different clades such as Entoleuca, Euepixylon, Kretzmaria, Nemania, Podosordaria, Poronia and Rosellinia. However, theoretically the HY clade (Xylaria "HY" clade II, Fig. 2) is the only acceptable cluster for strictly naming Xylaria species and other clades should represent other genera. Therefore, it is timely that xylaria-like taxa are resolved using both morphology and phylogeny.

This is not unique for Xylaria, but also similar for some other stromatic xylarialean taxa. Wendt et al. (2018) emphasized that ascal and ascospore characters have been the main discriminative criteria in traditional taxonomy and are artificial. Following a polyphasic taxonomic approach, Wendt et al. (2018) and Lambert et al. (2019) introduced several genera in Hypoxylaceae which were earlier placed in Hypoxylon. A similar approach should resolve the taxonomic confusion surrounding xylaria-like species. It is also not necessary to wait for a monograph as most of the old specimens cannot be sequenced and therefore, we can use fresh specimens to describe any new genera. Whether any old taxa are identical will be speculative, based on morphology and any combinations will be subjective (Dayarathne et al. 2016). Even though our new collection has superficial stromata similar to other Xylaria (sensu stricto) species, it is morphologically distinct in the palm host and perithecia which bulge from the stroma (as compared to immersed under a smooth stroma) and also phylogenetically distinct. The novel xylariacous genus, Neoxylaria is therefore introduced in this paper and will help to stabilize the classification of Xylariaceae. Phylogenetic analysis using three combined genes gave fair resolution for this order (Fig. 2).

Anthostomella-like species were also all clumped mostly under a single genus because they have immersed ascomata with or without a clypeus or a poorly or well-developed stroma, asci with a J+ or J- apical ring, dark unicellular ascospores (sometimes apiospores) with or without a germslit. Asci and ascospores were minute to large. Anthostomella-like taxa have now been shown to cluster in several different genera which are scattered in trees. Some authors used a single unique 
character to separate anthostomella-like taxa into distinct genera, such as Helicogermslita (Hawksworth \& Lodha 1983), which had spiral germ-slits but their introduction was subjective. One species that Duong et al. (2004) found was also anthostomella-like but introduced as a new genus Emarcea and eventually was shown to be sister to Induratia in a new family in Xylariales (Samarakoon et al. 2020). There are likely to be many other xylariaceous genera introduced in the future, just like as in Anthostomella.

We also introduced Stilbohypoxylon elaeidis as a new species confirmed by its phylogenetic placement. Stilbohypoxylon is polyphyletic and in this paper, we have defined Stilbohypoxylon sensu stricto and shows that $S$. quisquiliarum is distantly related and requires its own genus. Recent studies on tropical or poorly studied fungal genera have revealed an amazing diversity and numerous new species and this is likely to continue (Hyde et al. 2017, 2020). Thus, this study will help to resolve the naming and placement of the novel tropical taxa discoveries. Interestingly, Stilbohypoxylon sensu stricto (S. elaeidis and S. elaeidicola) occurred on the same host family, Arecaceae, with Neoxylaria, and they also share similar cultured characteristics. Both genera have cultured characteristics different from Xylaria sensu stricto, suggesting that both Stilbohypoxylon and Neoxylaria are likely ancient and related (but not the same genera) (Fig. 3 aa, ab, Fig. 4v).

Konta et al. (2016) reported appressoria formation in saprobic Oxydothis species. Xylaria species are mostly saprobes or endophytes and only a few species are pathogens (Miller \& Nielsen 1957, Kodsueb et al. 2008, Okane et al. 2008, Karun \& Sridhar 2015, Srihanant et al. 2015, Li et al. 2017, Adnan et al. 2018b, Chen et al. 2018, Debnath et al. 2018, Husbands \& Aime 2018). Xylaria species can also form appressoria when they germinate (Daranagama, pers obs). In the case of Neoxylaria arengae, we observed appressoria-like structures produced at the tips of germinating hyphae on media (Fig. 3t-z). Thus, it is interesting that Neoxylaria, Oxydothis and Xylaria species collected from palms produce appressoria which indicate they may have different life modes.

\section{Acknowledgments}

We are grateful to the National Research Council of Thailand (project no. 61215320023), the Mushroom Research Foundation and the Thailand Research Fund entitled "The future of specialist fungi in a changing climate: baseline data for generalist and specialist fungi associated with ants, Rhododendron species and Dracaena species” (Grant no: DBG6080013). Rungtiwa Phookamsak thanks CAS President's International Fellowship Initiative (PIFI) for young staff (Grant no. Y9215811Q1), the National Science Foundation of China (NSFC) project code 31850410489 (Grant no. Y81I982211) and Chiang Mai University for their support of this research work. Jianchu $\mathrm{Xu}$ thanks the Strategic Priority Research Program of Chinese Academy of Sciences and Key Research Program of Frontier Sciences of the Chinese Academy of Sciences (Grant no. QYZDYSSW-SMC014) for supporting this research. Saowaluck Tibpromma would like to thank the International Postdoctoral Exchange Fellowship Program (Number Y9180822S1), CAS President's International Fellowship Initiative (PIFI) (Number 2020PC0009), China Postdoctoral Science Foundation and the Yunnan Human Resources, and Social Security Department Foundation for funding her postdoctoral research. Sirinapa Konta express thanks to Key Laboratory for Plant Diversity and Biogeography of East Asia, Kunming Institute of Botany, Chinese Academy of Sciences for offering laboratory equipment to us for doing research on taxonomy and grateful to Yu-Ming Ju, Marc Stadler, Mingkwan Doilom, Samantha C. Karunarathna, Yuanpin Xiao, Wenjing Li, Ishani S. Goonasekara, Monika C. Dayarathne, Ausana Mapook, Chanokned Senwanna, Zeng Ming, Sirilak Radbouchoom, Anuruddha Karunarathna, Junfu Li, Paul Kirk, and Shaun Pennycook for their valuable suggestion and help.

\section{References}

Adnan M, Alshammari E, Ashraf SA, Patel K et al. 2018a - Physiological and molecular characterization of biosurfactant producing endophytic fungi Xylaria regalis from the cones 
of Thuja plicata as a potent plant growth promoter with its potential application. BioMed Research International 2018, 1-11.

Adnan M, Patel M, Reddy MN, Alshammari E. 2018b - Formulation, evaluation and bioactive potential of Xylaria primorskensis terpenoid nanoparticles from its major compound xylaranic acid. Scientific Reports 8, 1-12.

Becerril-Navarrete AM, Gómez-Reyes VM, Palestina Villa EN, Medel-Ortiz R. 2018 Nuevosregistros de Xylaria (Xylariaceae) para el estado de Michoacán, México. Scientia fungorum 48, 61-75.

Cedeño-Sanchez M, Wendt L, Stadler M, Mejia LC. 2020 - Three new species of Hypoxylon and new records of Xylariales from Panama. Mycosphere 11, 1457-1476.

Chen R, Tang JW, Li XR, Liu M et al. 2018 - Secondary metabolites from the endophytic fungus Xylaria sp. hg1009. Natural Products and Bioprospecting 8, 121-129.

Cooke MC. 1883 - On Xylaria and its allies. Grevillea 11, 81-94.

Daranagama DA, Camporesi E, Tian Q, Liu X et al. 2015 - Anthostomella is polyphyletic comprising several genera in Xylariaceae. Fungal Diversity 73, 203-238.

Daranagama DA, Hyde KD, Sir EB, Thambugala KM et al. 2018 - Towards a natural classification and backbone tree for Graphostromataceae, Hypoxylaceae, Lopadostomataceae and Xylariaceae. Fungal Diversity 88, 1-165.

Daranagama D, Jones E, Liu X, To-Anun C et al. 2016 - Mycosphere Essays 13-Do xylariaceous macromycetes make up most of the Xylariomycetidae?. Mycosphere 7, 582-601.

Dayarathne MC, Boonmee S, Braun U, Crous PW et al. 2016 - Taxonomic utility of old names in current fungal classification and nomenclature: Conflicts, confusion \& clarifications. Mycosphere 7, 1622-1648.

Debnath S, Majumdar K, Das P, Saha AK. 2018 - New distribution record of five species of Xylaria from Tripura, Northeast India. Research \& Reviews: A Journal of Life Sciences 8, 110.

Duong LM, Lumyong S, Hyde KD, Jeewon R. 2004 - Emarcea castanopsidicola gen. et sp. nov. from Thailand, a new xylariaceous taxon based on morphology and DNA sequences. Studies in Mycology 50, 253-260.

Elias LM, Fortkamp D, Sartori SB, Ferreira MC et al. 2018 - The potential of compounds isolated from Xylaria spp. as antifungal agents against anthracnose. Brazilian Journal of Microbiology 49, 840-847.

Esteban B, Perera TC, Romero AI, Hladki AI. 2013 - Stilbohypoxylon quisquiliarum (Ascomycota, Xylariaceae), nuevacita para la Argentina. Darwiniana 1, 289-294.

Fournier J, Ju YM, Hsieh HM, Lindemann U. 2018a - Xylaria aethiopica sp. nov. - a new podinhabiting species of Xylaria (Xylariaceae) from Ethiopia. Ascomycete.org 10, 209-215.

Fournier J, Lechat C, Courtecuisse R. 2018b - The genus Xylaria sensu lato (Xylariaceae) in Guadeloupe and Martinique (French West Indies) I. Taxa with penzigioid stromata. Ascomycete.org 10, 131-176.

Fröhlich J, Hyde KD. 2000 - Palm microfungi. Fungal Diversity Research Series. 3, 1-393.

Greville RK. 1824 - Flora Edinensis: Or A Description of Plants Growing Near Edinburgh with a Concise Introduction to the Natural Orders of the Class Cryptogamia: Blackwood.

Hawksworth DL, Lodha BC. 1983 - Helicogermslita, a new stromatic xylariaceous genus with a spiral germ slit from India. Transactions of the British Mycological Society 81, 91-96.

Hennings P. 1895 - Fungi camerunenses I. Botanische Jahrbücherfür Systematik Pflanzengeschichte und Pflanzengeographie 22, 72-111.

Hennings P. 1902 - Fungi blumenaviensis I, a cl. Alfr. Moller lecti. Hedwigia 41, 1-33.

Hennings P. 1904 - Fungi amazonici II, a cl. Ernesto Ulecollecti. Hedwigia 43, 262-263.

Hladki AI, Romero AI. 2003 - Two new species of Stilbohypoxylon and the taxonomic positions of Hypoxylon cyclopicum, H. chionostomum and Anthostoma chionostoma. Sydowia 55, 65-76. 
Hladki AI, Romero AI. 2010 - A preliminary account of Xylaria in the Tucuman Province, Argentina, with a key to the known species from the Northern Provinces. Fungal Diversity 42, 79-96.

Hongsanan S, Maharachchikumbura SSN, Hyde KD, Samarakoon MC et al. 2017 - An updated phylogeny of Sordariomycetes based on phylogenetic and molecular clock evidence. Fungal Diversity 84, 25-41.

Hsieh HM, Ju YM, Rogers JD. 2005 - Molecular phylogeny of Hypoxylon and closely related genera. Mycologia 97, 844-865.

Hsieh HM, Lin CR, Fang MJ, Rogers JD et al. 2010 - Phylogenetic status of Xylaria subgenus Pseudoxylaria among taxa of the subfamily Xylarioideae (Xylariaceae) and phylogeny of the taxa involved in the subfamily. Molecular Phylogenetics and Evolution 54, 957-969.

Huang G, Guo L, Liu N. 2014 - Two new species of Xylaria and X. diminuta new to China. Mycotaxon 129, 149-152.

Huelsenbeck JP, Ronquist F. 2001 - MRBAYES: Bayesian inference of phylogenetic trees. Bioinformatics 17, 754-755.

Husbands D, Aime M. 2018 - Emerging forest diseases: a case study of greenheart (Chlorocardium spp., Lauraceae) and the newly described fungus, Xylaria karyophthora. Forests 9, 365.

Husbands DR, Urbina H, Lewis SM, Aime MC. 2018 - Xylaria karyophthora: a new seedinhabiting fungus of Green heart from Guyana. Mycologia 110, 434-447.

Hyde KD, Maharachchikumbura SSN, Hongsanan S, Samarakoon MC et al. 2017 - The ranking of fungi: a tribute to David L. Hawksworth on his 70th birthday. Fungal Diversity 84, 1-23.

Hyde KD, Norphanphoun C, Maharachchikumbura SSN, Bhat DJ et al. 2020 - Refined families of Sodariomycetes. Mycosphere 11, 305-1059.

Index Fungorum. 2020 - http://www.indexfungorum.org/names/Names.asp. (Accessed January 2020).

Jaklitsch WM, Gardiennet A, Voglmayr H. 2016 - Resolution of morphology-based taxonomic delusions: Acrocordiella, Basiseptospora, Blogiascospora, Clypeosphaeria, Hymenopleella, Lepteutypa, Pseudapiospora, Requienella, Seiridium and Strickeria. Persoonia: Molecular Phylogeny and Evolution of Fungi 37, 82-105.

Jaklitsch WM, Voglmayr H. 2012 - Phylogenetic relationships of five genera of Xylariales and Rosasphaeria gen. nov. (Hypocreales). Fungal Diversity 52, 75-98.

Jayasiri SC, Hyde KD, Ariyawansa HA, Bhat DJ et al. 2015 - The Faces of Fungi database: fungal names linked with morphology, phylogeny and human impacts. Fungal Diversity 74, 3-18.

Johnston PR, Rogers JD, Park D, Martin NA. 2016 - Entalbostroma erumpens gen. et sp. nov. (Xylariaceae) from Phormium in New Zealand. Mycotaxon 131, 765-771.

Ju YM, Hsieh HM. 2007 - Xylaria species associated with nests of Odontotermes formosanus in Taiwan. Mycologia 99, 936-957.

Ju YM, Hsieh HM, Ho MC, Szu DH, Fang MJ. 2007 - Theissenia rogersii sp. nov. and phylogenetic position of Theissenia. Mycologia 99, 612-621.

Ju YM, Hsieh HM, Rogers JD, Fournier J et al. 2012 - New and interesting penzigioid Xylaria species with small, soft stromata. Mycologia 104, 766-776.

Ju YM, Rogers JD, Hsieh HM. 2018 - Xylaria species associated with fallen fruits and seeds. Mycologia 110, 726-749.

Karun N, Sridhar K. 2015 - Xylaria complex in the south western India. Plant Pathology \& Quarantine 5, 83-96.

Katoh K, Rozewicki J, Yamada KD. 2017 - Mafft online service: multiple sequence alignment, interactive sequence choice and visualization. Brief Bioinform.

Kodsueb R, McKenzie E, Lumyong S, Hyde K. 2008 - Diversity of saprobic fungi on Magnoliaceae. Fungal Diversity 30, 37-53.

Konta S, Hongsanan S, Tibpromma S, Thongbai B et al. 2016 - An advance in the endophyte story: Oxydothidaceae fam. nov. with six new species of Oxydothis. Mycosphere 7, 1425-1446. 
Konta S, Maharachchikumbura SSN, Senanayake IC, McKenzie EHC et al. 2020 - A new genus Allodiatrype, five new species and a new host record of diatrypaceous fungi from palms (Arecaceae). Mycosphere 11, 239-268.

Koyani R, Patel H, Vasava A, Rajput K. 2016 - Xylariaceae: overview and addition to fungal diversity of Gujarat state. Studies in Fungi 1, 69-79.

Kumar S, Stecher G, Tamura K. 2016 - MEGA7: molecular evolutionary genetics analysis version 7.0 for bigger datasets. Molecular Biology and Evolution 33, 1870-1874.

Lambert C, Wendt L, Hladki AI, Stadler M, Sir EB. 2019 - Hypomontagnella (Hypoxylaceae): a new genus segregated from Hypoxylon by a polyphasic taxonomic approach. Mycological Progress 18, 187-201.

Lee JS, Ko KS, Jung HS. 2000 - Phylogenetic analysis of Xylaria based on nuclear ribosomal ITS1-5.8 S-ITS2 sequences. FEMS Microbiology Letters 187, 89-93.

Li Q, Liu L, Zhang X, Shen X, Kang J. 2017 - Xylaria spinulosa sp. nov. and X. strosphaerica from China. Mycosphere 8, 1070-1079.

Li QR, Kang JC, Hyde KD. 2015a - Two new species of the genus Collodiscula (Xylariaceae) from China. Mycological progress 14, 52.

Li Q, Wen TC, Kang JC, Hyde KD. 2015b - A new species of Collodiscula (Xylariaceae) from China. Phytotaxa 205, 187-196.

Liu YJ, Whelen S, Hall BD. 1999 - Phylogenetic relationships among ascomycetes: evidence from an RNA polymerase II subunit. Molecular Biology and Evolution 16, 1799-1808.

Maharachchikumbura SSN, Hyde KD, Jones EBG, McKenzie EHC et al. 2016 - Families of Sordariomycetes. Fungal Diversity 79, 1-317.

Martin P. 1970 - Studies in the Xylariaceae: VIII. Xylaria and its allies. Journal of South African Botany 36, 73-137.

Miller JH. 1961 - A monograph of the world species of Hypoxylon. University of Georgia Press, Athens, 158 pp.

Miller JH, Nielsen L. 1957 - A new species of Xylaria. Mycologia 49, 112-114.

Montagne JPFC. 1840 - Séconde centurie de plantes cellulaires exotiques nouvelles, Décades VI, VII et VIII. Annales des Sciences Naturelles Botanique 14, 321-350.

Narula A, Rawla G, Kaushal S. 1985 - Two new species of Xylaria (Pyrenomycetes) from India. Willdenowia 409-411.

Nylander J. 2004 - MrModeltest v2. Program distributed by the author. Evolutionary Biology Centre, Uppsala University, Uppsala.

Okane I, Toyama K, Nakagiri A, Læssøe T et al. 2008 - Study of endophytic Xylariaceae in Thailand: diversity and taxonomy inferred from rDNA sequence analyses with saprobes forming fruit bodies in the field. Mycoscience 49, 359-372.

O’Donnell K, Cigelnik E. 1997 - Two divergent intragenomic rDNA ITS2 types within a monophyletic lineage of the fungus Fusarium are nonorthologous. Molecular Phylogenetics and Evolution 7, 103-116.

Peláez F, González V, Platas G, Sánchez Ballesteros J, Rubio V. 2008 - Molecular phylogenetic studies within the Xylariaceae based on ribosomal DNA sequences. Fungal Diversity 31, 111-134.

Peršoh D, Melcher M, Graf K, Fournier J et al. 2009 - Molecular and morphological evidence for the delimitation of Xylaria hypoxylon. Mycologia 101, 256-268.

Petrini LE. 2003 - Rosellinia and related genera in New Zealand. New Zealand Journal of Botany 41, 71-138.

Petrini LE. 2004 - A revision of the genus Stilbohypoxlon (Xylariaceae). Sydowia 56, 51-71.

Pourmoghaddam MJ, Khodaparast SA, Krisai-Greilhuber I, Voglmayr H, Stadler M. 2018 - Two new species and one new record of Kretzschmaria (Ascomycota, Xylariales) from Iran. Mycosphere 9, 1197-1208.

Rambaut A. 2006 - FigTree. Tree figure drawing tool version 1.4. 0. University of Edinburgh: Institute of Evolutionary Biology, (http://tree.bio.ed.ac.uk/software/figtree/). 
Rogers JD, Ju YM. 1997 - The genus Stilbohypoxylon. Mycological Research 101, 135-138.

Rogers JD. 2000 - Thoughts and musings on tropical Xylariaceae. Mycological Research 104, $1412-1420$.

Samarakoon M, Hyde KD, Promputtha I, Ariyawansa H, Hongsanan S. 2016 - Divergence and ranking of taxa across the kingdoms Animalia, Fungi and Plantae. Mycosphere 7, 1678-1689.

Samarakoon MC, Thongbai B, Hyde KD, Brönstrup M et al. 2020 - Elucidation of the life cycle of the endophytic genus Muscodor and its transfer to Induratia in Induratiaceae fam. nov., based on a polyphasic taxonomic approach. Fungal Diversity 101, 177-210.

Schrank FvP. 1789 - Baierische Flora. 1, 1-753.

Senanayake IC, Maharachchikumbura SSN, Hyde KD, Bhat DJ et al. 2015 - Towards unraveling relationships in Xylariomycetidae (Sordariomycetes). Fungal Diversity 73, 73-144.

Silvestro D, Michalak I. 2012 - raxmlGUI: a graphical front-end for RAxML. Organisms Diversity \& Evolution 12, 335-337.

Srihanant N, Petcharat V, Vasilyeva LN. 2015 - Xylaria thailandica - a new species from southern Thailand. Mycotaxon 130, 227-231.

Stadler M, Hellwig V. 2005 - Chemotaxonomy of the Xylariaceae and remarkable bioactive compounds from Xylariales and their associated asexual stages. Research Signpost 41-93.

Stadler M, Kuhnert E, Peršoh D, Fournier J. 2013 - The Xylariaceae as model example for a unified nomenclature following the "One Fungus-One Name" (1F1N) concept. Mycology 4, 5-21.

Stamatakis A. 2006 - RAxML-VI-HPC: maximum likelihood-based phylogenetic analyses with thousands of taxa and mixed models. Bioinformatics 22, 2688-2690.

Tang AM, Jeewon R, Hyde KD. 2007 - Phylogenetic relationships of Nemania plumbea sp. nov. and related taxa based on ribosomal ITS and RPB2 sequences. Mycological Research 111, 392-402.

Tang A, Jeewon R, Hyde KD. 2009 - A re-evaluation of the evolutionary relationships within the Xylariaceae based on ribosomal and protein-coding gene sequences. Fungal Diversity 34, 127-155.

Taylor JE, Hyde KD. 2003 - Microfungi of tropical and temperate palms. Fungal Diversity Research series 12, 121-459.

Tibpromma S, Hyde KD, Jeewon R, Maharachchikumbura SSN et al. 2017 - Fungal diversity notes 491-602: taxonomic and phylogenetic contributions to fungal taxa. Fungal Diversity 83, 1261.

U’Ren JM, Miadlikowska J, Zimmerman NB, Lutzoni F et al. 2016 - Contributions of North American endophytes to the phylogeny, ecology, and taxonomy of Xylariaceae (Sordariomycetes, Ascomycota). Molecular Phylogenetics and Evolution 98, 210-232.

Voglmayr H, Friebes G, Gardiennet A, Jaklitsch WM. 2018 - Barrmaelia and Entosordaria in Barrmaeliaceae (fam. nov., Xylariales) and critical notes on Anthostomella-like genera based on multigene phylogenies. Mycological Progress 17, 155-177.

Vu D, Groenewald M, De Vries M, Gehrmann T et al. 2019 - Large-scale generation and analysis of filamentous fungal DNA barcodes boosts coverage for kingdom fungi and reveals thresholds for fungal species and higher taxon delimitation. Studies in Mycology 92, 135-154.

Wendt L, Sir EB, Kuhnert E, Heitkämper S et al. 2018 - Resurrection and emendation of the Hypoxylaceae, recognised from a multigene phylogeny of the Xylariales. Mycological Progress 17, 115-154.

White TJ, Bruns T, Lee SJWT, Taylor JW. 1990 - Amplification and direct sequencing of fungal ribosomal RNA genes for phylogenetics. PCR Protocols: A Guide to Methods and Applications 18, 315-322.

Wijayawardene NN, Hyde KD, Lumbsch HT, Liu JK et al. 2018 - Outline of ascomycota: 2017. Fungal Diversity 88, 167-263.

Wijayawardene NN, Hyde KD, Al-Ani LKT, Tedersoo L et al. 2020 - Outline of Fungi and fungus-like taxa. Mycosphere 11, 1060-1456. 